\title{
Novel $\mathrm{Pb}(\mathrm{II})$ ion-imprinted materials based on bis-pyrazolyl
}

\section{functionalized mesoporous silica for the selective removal of $\mathrm{Pb}(\mathrm{II})$ in}

\section{water samples}

He-Zhen Cui ${ }^{\mathrm{a}, \mathrm{b}}$, Yuan-Long $\mathrm{Li}^{\mathrm{b}}$, Shu Liu ${ }^{\mathrm{c}}$, Jin-Fan Zhang ${ }^{\mathrm{b}}$, Quan Zhou ${ }^{\mathrm{b}}$, Rui Zhong ${ }^{\mathrm{b}}$, Min-Li Yang ${ }^{\mathrm{a}}$, Xiu-Feng Hou ${ }^{\mathrm{b}, *}$

${ }^{a}$ College of Life and Environmental Science, Shanghai Normal University, 100 Guilin Road, Shanghai 200234

${ }^{\mathrm{b}}$ Department of Chemistry, Fudan University, 220 Handan Road, Shanghai 200433, China

${ }^{\mathrm{c}}$ Technical Center for Industrial Product and Raw Material Inspection and Testing, Shanghai Entry-Exit Inspection and Quarantine Bureau, Shanghai 200135, China.

\begin{abstract}
Three highly efficient adsorbents Pb-IIMS-SBA-15, Pb-IIMS-MCM-41 and $\mathrm{Pb}$-IIMS-FDU-12 for $\mathrm{Pb}(\mathrm{II})$ were prepared by grafting the functional monomer 4-(di (1H-pyrazol-1-yl) methyl) phenol (DPP) on corresponding mesoporous silicas with $\mathrm{Pb}(\mathrm{II})$ as temple. All these three $\mathrm{Pb}$ (II) ion-imprinted mesoporous silica ( $\mathrm{Pb}$-IIMS) were characterized by Fourier transform-infrared spectroscopy (FT-IR), solid-state ${ }^{29} \mathrm{Si}$ and ${ }^{13} \mathrm{C}$ NMR spectra, scanning electron microscopy (SEM), transmission electron microscopy (TEM), energy dispersive X-ray spectroscopy (EDX), $\mathrm{N}_{2}$ adsorption-desorption analysis and small angel X-ray diffraction (XRD). The adsorption experiments revealed three $\mathrm{Pb}$-IIMS all possessed considerable adsorption performance for $\mathrm{Pb}(\mathrm{II})$, their adsorption profiles obeyed pseudo-second-order kinetics and Langmuir isotherm model. Compared with their corresponding non-imprinted materials, three $\mathrm{Pb}$-IIMS displayed satisfactory selectivity to $\mathrm{Pb}(\mathrm{II})$ over seven competing metal ions. Among them, $\mathrm{Pb}$-IIMS-MCM-41 particularly owned outstanding adsorption performance and selectivity, the maximum adsorption capacity as high as $344.8 \mathrm{mg} \mathrm{g}^{-1}$, as well as excellent reusability through twelve adsorption-desorption cycles. Additionally,
\end{abstract}


Pb-IIMS-MCM-41 was employed as packing material to construct a solid-phase extraction column for detection of $\mathrm{Pb}(\mathrm{II})$, which exhibited detection limit of $0.015 \mu \mathrm{g}$ $\mathrm{L}^{-1}$, then method was successfully applied to the removal and determination of trace $\mathrm{Pb}(\mathrm{II})$ in practical water samples.

Keywords: $\mathrm{Pb}(\mathrm{II})$, ion-imprinted mesoporous silica, bis-pyrazolyl functional monomer, selective adsorption, solid-phase extraction column

\section{Introduction}

Heavy metals, due to their non-biodegradability and accumulation in environment and living body, become more noticeable for human beings [1,2]. Lead $(\mathrm{Pb}(\mathrm{II}))$ is one of most toxic and plentiful heavy metals with important environmental and toxicological significances [3]. Hence, determination or removal of $\mathrm{Pb}(\mathrm{II})$ is highly demanded for the sustainability of environment. At present, a lot of methods and technologies, such as ion-exchange method [4], chemical precipitation [5], and adsorption [6,7] are applied to remove $\mathrm{Pb}(\mathrm{II})$ ions. However, most of these methods have the same disadvantage on their selectivity. Thus, it is strong required to develop more effective methods for selectively removal of $\mathrm{Pb}(\mathrm{II})$.

Ion imprinted polymers (IIPs), which are developed to mimic the binding cavities of biological compounds for an improved recognition of the template ions, are attractive solid sorbent for selective separation of metal ions [8]. The synthesis of IIPs generally includes the preparation of a monomer-metal complex and its further copolymerization with a cross-linker to eventually obtain 3-D recognition sites inside the polymeric network [9]. So far, various functional monomer such as methylacrylic acid (MAA) [10,11], 4-vinyl pyridine (4-VP) [12,13], chitosan [14-16], organic silane [17-19] and amine [20,21] have been employed for the preparation of the $\mathrm{Pb}(\mathrm{II})$ complexes. And the IIPs with amine functionalities were found to be the most effective ones for the adsorption and separation of $\mathrm{Pb}$ (II) $[20,21]$. However, owing to their tendency to oxidation, organic amines have poor chemical stability. 
Consequently, an alternative ligand system is desired to further develop stable and effective IIPs for the adsorption and separation of $\mathrm{Pb}$ (II).

Recently, the utilization of mesoporous silica materials as solid support for adsorption of toxic substances [22-24] such as the separation and preconcentration of heavy metals have gained considerable attention, due to their high surface area, good chemical and mechanical stability, fast adsorption rate as well as tunable profile [25-27]. Furthermore, it was found that the mesoporous silica materials could exhibit increased separation efficiency for heavy metals with functional monomers attached [28-33]. He et al. reported a $\mathrm{Pb}(\mathrm{II})$ ion-imprinted SBA-15 type mesoporous silica material, by using amino carboxylic acid as functional group, for selective removal of $\mathrm{Pb}$ (II) [31]. Liu et al. synthesized a highly selective mesoporous adsorbent with fast kinetics for adsorption of $\mathrm{Pb}(\mathrm{II})$ by grafting functional monomer chitosan onto SBA-15 [14]. Meng et al. described the preparation of an ion-imprinted SBA-15 material modified by functional monomer of 4-VP for effective removal of $\mathrm{Ce}^{3+}$ ion [32].

With this context and our former experience on modification of mesoporous silica materials [34-36], we herein report the preparation of a series of highly selective $\mathrm{Pb}$ (II) ion-imprinted mesoporous silica materials ( $\mathrm{Pb}$-IIMS) for separation of $\mathrm{Pb}(\mathrm{II})$. In this work, DPP, which processed a $N, N$-bidentate group was selected as functional group to interact with the template ion $\mathrm{Pb}(\mathrm{II})$, therefore preparing a monomer/metal complex. This complex was then grafted to three kinds of mesoporous silica materials SBA-15, MCM-41 and FDU-12, respectively, synthesizing Pb-IIMS-SBA-15, Pb-IIMS-MCM-41, Pb-IIMS-FDU-12. Furthermore, the morphologies and structures of the as-prepared $\mathrm{Pb}$-IIMS were fully characterized by various analytic tools. In addition, static and dynamic adsorptions and a set of operational parameters such as $\mathrm{pH}$, the stripping agent of $\mathrm{Pb}(\mathrm{II})$, selectivity, effects of interfering ions and reusability were systematically investigated by inductively coupled plasma-atomic emission spectrometry (ICP-AES). Finally, the method of Pb-IIMS-MCM-41 filled solid-phase extraction (SPE) column coupled with inductively coupled plasma-atomic mass spectrometry (ICP-MS) was developed for removal and determination of trace $\mathrm{Pb}$ (II) 
in real water samples, which further confirmed the practical applicability of Pb-IIMS-MCM-41.

\section{Experimental}

\subsection{Reagents and methods}

All chemical reagents and materials were obtained from commercial sources and used without further purification. Deionized water was obtained from Milli-Q Plus water purification system.

NMR spectra were measured using Bruker spectrometers operating at $400 \mathrm{MHz}\left({ }^{1} \mathrm{H}\right)$ and $100 \mathrm{MHz}\left({ }^{13} \mathrm{C}\right)$ in $\mathrm{CDCl}_{3}$. Solid-state ${ }^{13} \mathrm{C}$ and ${ }^{29} \mathrm{Si} \mathrm{CP}$ MAS NMR spectra were performed at $100.6 \mathrm{MHz}$ using a Bruker $\mathrm{AV}-400$ spectrometer. Fourier transform infrared (FT-IR) spectra in KBr were analyzed on a Nicolet AVATAR-360 IR. Small angel X-ray diffraction (XRD) measurements were measured with a Bruker D4 powder X-ray scattering using $\mathrm{Cu} \mathrm{K} \alpha$ radiation $(45 \mathrm{kV}, 650 \mathrm{~mA})$. Transmission election microscopy (TEM) images were conducted with a JEOL JEM 2010 electron microscope at $200 \mathrm{kV}$. Energy dispersive X-ray spectroscopy (EDX) and scanning electron microscopy (SEM) were recorded using a Phenom Prox at an acceleration voltage of $4.8 \mathrm{kV}$ to $15 \mathrm{kV}$. Nitrogen adsorption isotherms were measured at $77 \mathrm{~K}$ after being outgassed at $383 \mathrm{~K}$ overnight on a Quantachrome Nova 4000 analyzer. Pore size distributions and specific surface areas (SBET) were calculated using the BJH model and the BET method, respectively.

\subsection{Preparation of $P b(I I)$ ion-imprinted mesoporous silica}

\subsubsection{Synthesis of 4-(di (1H-pyrazol-1-yl) methyl) phenol (DPP)}

The synthesis method for preparation of DPP was modified according to the reference [37]. Pale yellow powder, Yield 51\%. ${ }^{1} \mathrm{H}$ NMR (400 MHz, $\left.\mathrm{CD}_{3} \mathrm{OD}, \mathrm{ppm}\right): \delta$ 6.39-6.40 (m, 2H), 6.80-6.82 (d, 2H), 6.91-6.93 (d, 2H), 7.62-7.63 (m, 4H), 7.78(s, $1 \mathrm{H})$. 


\subsubsection{Preparation of lead complex}

First, $2 \mathrm{mmol}$ of DPP (480 mg) were dissolved in $50 \mathrm{~mL}$ of methanol in a $250 \mathrm{~mL}$ Erlenmeyer flasks. Subsequently, $1 \mathrm{mmol}$ of $\mathrm{Pb}\left(\mathrm{NO}_{3}\right)_{2}(331 \mathrm{mg})$ as an imprinted metal ion (template) was added slowly to a glass flask and the resultant mixture was stirred for $5 \mathrm{~h}$ at room temperature. After filtering and drying, the light yellow powder was obtained (770 mg, 95\%). ${ }^{1} \mathrm{H}$ NMR (400 MHz, $\left.\mathrm{CD}_{3} \mathrm{OD}, \mathrm{ppm}\right): \delta 6.39-6.4$ (m, 2H), 6.8-6.82 (d, 2H), 6.91-6.93 (d, 2H), 7.62-7.63 (m, 4H), 7.78(s, 1H). ${ }^{13} \mathrm{C}-\mathrm{NMR}(400$ $\left.\mathrm{MHz}, \mathrm{CDCl}_{3}, \mathrm{ppm}\right): \delta 77.11,106.05,115.20,126.44,128.43,130.04,140.30,158.30$.

\subsubsection{Synthesis of $\mathrm{Pb}(\mathrm{II})$ ion imprinted and non-ion imprinted} mesoporous silicas

$\mathrm{Pb}$ (II) ion-imprinted mesoporous silicas were obtained by following the procedure: 1 mmol of lead complex $(811 \mathrm{mg})$ was dissolved in $80 \mathrm{~mL}$ tetrahydrofuran with stirring, and $1 \mathrm{mmol}$ dehydrated $\mathrm{K}_{2} \mathrm{CO}_{3}(138 \mathrm{mg})$ was added to the solution. After 2 hours, 1 mmol (247 mg) 3-(triethoxysilyl)-propyl-isocyanate (TEPIC) was added into the solution drop by drop. The whole mixture was refluxed at $65{ }^{\circ} \mathrm{C}$ for 12 hours, the solvent was dried under vacuum. The resultant solid dissolved in $20 \mathrm{~mL}$ toluene, followed by adding $973 \mathrm{mg}$ of SBA-15, MCM-41, FDU-12, then reflux for $48 \mathrm{~h}$ at $110{ }^{\circ} \mathrm{C}$, respectively. After filtration, resulting solid was repeatedly washed with dichloromethane, distilled water, ethanol and ethyl acetate, then dried under vacuum. Each $5 \mathrm{mg}$ of obtained materials washed by $10 \mathrm{~mL}, 3 \mathrm{~mol} \mathrm{~L}^{-1} \mathrm{HCl}$ to elute the template lead. After drying, $\mathrm{Pb}$ (II) ion-imprinted mesoporous silicas (Pb-IIMS) were gained, namely Pb-IIMS-SBA-15, Pb-IIMS-MCM-41, Pb-IIMS-FDU-12.

The corresponding non-imprinted mesoporous silicas (NIMS) DPP@SBA-15, DPP@MCM-41, DPP@FDU-12 were synthesized by using DPP as monomer, the following procedure was the same as that of IIMS without eluting.

\subsection{Adsorption experiment}

To investigate the effect of $\mathrm{pH}, 5 \mathrm{mg}$ Pb-IIMS-SBA-15, Pb-IIMS-MCM-41, $\mathrm{Pb}$-IIMS-FDU-12 were added to $20 \mathrm{~mL}$ sample solutions containing $5 \mathrm{mg} \mathrm{L}^{-1}$ of $\mathrm{Pb}$ (II) 
ion at $\mathrm{pH}$ range 2.0-8.0, respectively, $\mathrm{pH}$ values were adjusted by $1 \mathrm{~mol} \mathrm{~L}^{-1} \mathrm{HNO}_{3}$ and $1 \mathrm{~mol} \mathrm{~L}{ }^{-1} \mathrm{NaOH}$. The mixture was continuously bath oscillated for $30 \mathrm{~min}$ at $25{ }^{\circ} \mathrm{C}$, and then placed stably for 30 min, centrifugation, filtration, the concentration of $\mathrm{Pb}$ (II) in upper solutions were measured by (ICP-AES). To choose the optimal $\mathrm{pH}$, we studied the extraction efficiency. As comparison, we also researched the influence of $\mathrm{pH}$ on non-ion imprinted polymers. The extraction efficiency was calculated with the following equation:

Extraction efficiency $(\%)=\frac{\left(\mathrm{C}_{0}-\mathrm{C}_{\mathrm{e}}\right)}{\mathrm{C}_{\mathrm{o}}} \times 100$

Where $\mathrm{C}_{\mathrm{o}}$ and $\mathrm{C}_{\mathrm{e}}$ are the concentrations of lead ion at original and equilibrium state in the solution.

For desorption of $\mathrm{Pb}$ (II) functionalized mesoporous silica, a series of selected elution solutions, such as $\mathrm{HNO}_{3}, \mathrm{HCl}$ at different concentrations, were considered.

To investigate the adsorption capacity of three kinds of $\mathrm{Pb}$-IIMS and the corresponding NIMS, $5 \mathrm{mg}$ of each adsorption dispersed in $20 \mathrm{~mL}$ aqueous solutions containing different contents of $\mathrm{Pb}$ (II) (5-70 ppm) at their optimal $\mathrm{pH}$ values, respectively. Then the mixture was continuously bath oscillated for $30 \mathrm{~min}$ at $25{ }^{\circ} \mathrm{C}$, and then placed stably for $30 \mathrm{~min}$, centrifugation, filtration, the concentration of the $\mathrm{Pb}(\mathrm{II})$ in upper solutions were measured by ICP-AES.

The adsorption capacity was calculated by the following equation:

$$
\mathrm{q}_{\mathrm{e}}=\frac{\left(\mathrm{C}_{\mathrm{o}}-\mathrm{C}_{\mathrm{e}}\right) \mathrm{V}}{\mathrm{m}}
$$

Where $\mathrm{q}_{\mathrm{e}}$ (adsorption capacity, $\mathrm{mg} \mathrm{g}^{-1}$ ) is amount of $\mathrm{Pb}(\mathrm{II})$ adsorbed by $\mathrm{Pb}$-IIMS, $\mathrm{C}_{\mathrm{o}}$ and $\mathrm{C}_{\mathrm{e}}$ are original and equilibrated concentration of $\mathrm{Pb}(\mathrm{II})$ in solutions separately, $\mathrm{m}$ (g) is the weight of IIMS, V (L) is the volume of $\mathrm{Pb}(\mathrm{II})$ ion solution.

In a meanwhile, kinetic studies for $\mathrm{Pb}(\mathrm{II})$ were conducted to determine the adsorption rate of $\mathrm{Pb}(\mathrm{II})$ from water samples as follows: $5 \mathrm{mg}$ of each sorbent were dispersed in $20 \mathrm{~mL}$ solution containing the same initial $\mathrm{Pb}(\mathrm{II})$ concentration of $90 \mathrm{ppm}$. Each of the mixture was continuously bath oscillated at $25{ }^{\circ} \mathrm{C}$ for $10,20,30,40$ or $50 \mathrm{~min}$. After each time period, solutions were filtered and analyzed by ICP-AES to determine the concentration of $\mathrm{Pb}(\mathrm{II})$ in the final solution. 


\subsection{Selectivity studies}

To study of specific and selective adsorption to $\mathrm{Pb}(\mathrm{II})$, the adsorption performance of our three ion-imprinted materials and their corresponding non-imprinted materials were conducted in a mixed ion solution containing $\mathrm{Cd}(\mathrm{II}), \mathrm{Co}(\mathrm{II}), \mathrm{Cu}(\mathrm{II}), \mathrm{Pb}(\mathrm{II})$, $\mathrm{Hg}(\mathrm{II}), \mathrm{Mg}(\mathrm{II}), \mathrm{Mn}(\mathrm{II}), \mathrm{Zn}(\mathrm{II})$ as competitive ions, the amount of IIMS and NIMS are all $5 \mathrm{mg}$, the initial concentrations of these ions are all $20 \mathrm{ppm}$. Then the mixture was continuously bath oscillated for $30 \mathrm{~min}$ at $25^{\circ} \mathrm{C}$, and then placed stably for $30 \mathrm{~min}$, centrifugation, filtration. The ICP-AES is used to measure the concentration of Cd(II), $\mathrm{Co}(\mathrm{II}), \mathrm{Cu}(\mathrm{II}), \mathrm{Pb}(\mathrm{II}), \mathrm{Hg}(\mathrm{II}), \mathrm{Mg}(\mathrm{II}), \mathrm{Mn}(\mathrm{II}), \mathrm{Zn}$ (II) before and after adsorption. Distribution coefficient $\mathrm{K}_{\mathrm{d}}\left(\mathrm{mL} \mathrm{g}^{-1}\right)$, selectivity coefficient $(\alpha)$, relative selectivity coefficient $(\beta)$ were calculated based on the following equations:

$\mathrm{K}_{\mathrm{d}}=\frac{\left(\mathrm{C}_{\mathrm{o}}-\mathrm{C}_{\mathrm{e}}\right) \mathrm{V}}{\mathrm{C}_{\mathrm{e}} \mathrm{m}}$

$\alpha=\frac{\mathrm{K}_{\mathrm{d} 1}}{\mathrm{~K}_{\mathrm{d} 2}}$

$\beta=\frac{\alpha_{1}}{\alpha_{2}}$

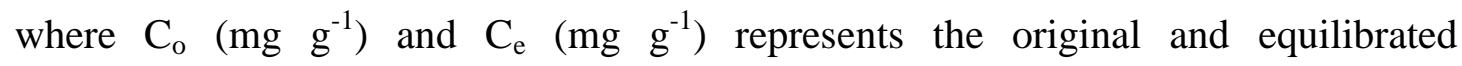
concentration of $\mathrm{Pb}(\mathrm{II}) ; \mathrm{m}(\mathrm{g})$ is the weight of IIMS, $\mathrm{V}(\mathrm{L})$ is the volume of $\mathrm{Pb}(\mathrm{II})$ ion solution; $\mathrm{K}_{\mathrm{d} 1}$ and $\mathrm{K}_{\mathrm{d} 2}$ are the distribution coefficient of $\mathrm{Pb}(\mathrm{II})$ and the competitive ions, respectively; $\alpha_{1}$ and $\alpha_{2}$ denote the selectivity coefficient of ion-imprinted materials and non-ion-imprinted materials, respectively.

To investigate the inference of various cations in natural samples, the tests were carried out by using the same amount of $\mathrm{Li}(\mathrm{I}), \mathrm{Na}(\mathrm{I}), \mathrm{K}(\mathrm{I}), \mathrm{Mg}(\mathrm{II}), \mathrm{Mn}(\mathrm{II}), \mathrm{Co}(\mathrm{II})$, $\mathrm{Cd}(\mathrm{II}), \mathrm{Ba}(\mathrm{II}), \mathrm{Hg}(\mathrm{II}), \mathrm{Cr}(\mathrm{III}), \mathrm{Cu}(\mathrm{II}), \mathrm{Cl}^{-}, \mathrm{SO}_{4}{ }^{2-}, \mathrm{CH}_{3} \mathrm{COO}^{-}, \mathrm{NH}_{4}{ }^{+}$as concomitant ions added to $20 \mathrm{~mL}$ of solution containing $0.5 \mathrm{ppm} \mathrm{Pb}(\mathrm{II})$. The aqueous mixtures of $\mathrm{X} / \mathrm{Pb}$ (II) mixed with $5 \mathrm{mg}$ Pb-IIMS-SBA-15, Pb-IIMS-MCM-41, Pb-IIMS-FDU-12 and their corresponding NIMS respectively, the mixture was continuously bath oscillated for $30 \mathrm{~min}$ at $25{ }^{\circ} \mathrm{C}$, and then placed stably for $30 \mathrm{~min}$, centrifugation, filtration, the concentration of $\mathrm{Pb}$ (II) in the final solution were determined by ICP-AES. We used extraction efficiencies of adsorbents towards $\mathrm{Pb}(\mathrm{II})$ to illustrate 
anti-interference of our adsorbents in the condition of the presence of interfering ions.

\subsection{Reusability studies of Pb-IIMS-MCM-41}

The adsorption-deposition experiments were conducted to show the reusability of Pb-IIMS-MCM-41. First, 5 mg Pb-IIMS-MCM-41 were dispersed in $20 \mathrm{~mL}$ of 5ppm $\mathrm{Pb}$ (II) standard solution ( $\mathrm{pH} 6.0$ ), consecutively bath oscillated for $30 \mathrm{~min}$ at $25{ }^{\circ} \mathrm{C}$. The adsorbed $\mathrm{Pb}(\mathrm{II})$ on $5 \mathrm{mg}$ Pb-IIMS-MCM-41 was desorbed by $10 \mathrm{~mL}, 3 \mathrm{~mol} \mathrm{~L}^{-1}$ $\mathrm{HCl}$, then bath oscillated for $30 \mathrm{~min}$ at $25{ }^{\circ} \mathrm{C}$, the released $\mathrm{Pb}(\mathrm{II})$ in the supernatant were determined by ICP-AES. By using the identical adsorbent to accomplish twelve cycles of adsorption-deposition experiments, the reusability assessment of $\mathrm{Pb}$-IIMS-MCM-41 were obtained.

\subsection{The application of Pb-IIMS-MCM-41 packed SPE column}

The SPE cartridge was prepared by packing $200 \mathrm{mg}$ Pb-IIMS-MCM-41 in a column (12.8 mm, i.d.), which were preconditioned with $3 \mathrm{~mol} / \mathrm{L} \mathrm{HCl}(5 \mathrm{~mL})$ and deionized water $(5 \mathrm{~mL})$ at a flow rate of $1.0 \mathrm{~mL} \mathrm{~min}^{-1}$. The prepared water sample solutions $(5$ $\mathrm{mL}$ ) were passed through cartridges at a flow rate of $0.2 \mathrm{~mL} \mathrm{~min}^{-1}$, respectively. The cartridges were washed with deionized water $(5 \mathrm{~mL})$, after that, the absorbed $\mathrm{Pb}^{2+}$ was eluted with $2.5 \mathrm{~mL}$ of $3 \mathrm{~mol} / \mathrm{L} \mathrm{HCl}$ at a flow rate of $0.5 \mathrm{~mL} \mathrm{~min}^{-1}$. Ultimately, the obtained extractions were determined by ICP-MS.

Tap water and river water sample were collected from laboratory, Huangpu River (Shanghai, China), respectively, then centrifuged and filtered to remove the suspended particles. The resultant filtrates spiked with two concentrations of $\mathrm{Pb}$ (II) standards (5 $\mu \mathrm{g} \mathrm{L}{ }^{-1}, 10 \mu \mathrm{g} \mathrm{L}^{-1}$ ), the resultant mixture were adjusted to $\mathrm{pH} 6.0 \mathrm{using} 1 \mathrm{~mol} \mathrm{~L}^{-1} \mathrm{HNO}_{3}$ and $1 \mathrm{~mol} \mathrm{~L}^{-1} \mathrm{NaOH}$, and three repeated experiments have been done for each concentration, respectively.

\section{Results and discussion}

\subsection{Preparation}

The stepwise preparation of Pb-IIMS was illustrated in Scheme 1. The DPP was 
synthesized by the reaction between pyrazole and $p$-hydroxybenzaldehyde in THF, then DPP chelated with $\mathrm{Pb}$ (II) to obtained the lead complex. The resultant complex cross-linked with three kinds of mesoporous silica SBA-15, MCM-41, FDU-12 by using TEPIC, respectively. The cross-linking reaction occurred between phenolic hydroxyl groups of DPP and isocyanate of TEPIC, afterwards grafted on mesoporous silica through $\mathrm{Si}-\mathrm{OH}$ of mesoporous. Subsequent removal of chelated $\mathrm{Pb}(\mathrm{II})$ by $\mathrm{HCl}$ solution to obtain the $\mathrm{Pb}(\mathrm{II})$ ion-imprinted mesoporous silica adsorbents Pb-IIMS-SBA-15, Pb-IIMS-MCM-41, Pb-IIMS-FDU-12.

\section{Scheme 1}

\subsection{Characterization}

Fig. 1 displays the FT-IR spectra of DPP and Pb-IIMS. All Pb-IIMS can be seen the stretching vibration of near 3423 and $1629 \mathrm{~cm}^{-1}$ attribute to variety vibration and inplane bending vibration of surface $\mathrm{Si}-\mathrm{OH}$. The adsorption bands near 1084, 807, $463 \mathrm{~cm}^{-1}$ were attributed to the stretching and bending vibration of $\mathrm{Si}-\mathrm{O}-\mathrm{Si}$ on mesoporous silicas. In addition, the adsorption band near $2940 \mathrm{~cm}^{-1}$ was assigned to $\mathrm{C}-\mathrm{H}$ stretching vibration of organic groups [38-41]. These spectra preliminary confirmed that Pb-IIMS-SBA-15, Pb-IIMS-MCM-41, Pb-IIMS-FDU-12 were prepared.

\section{Fig. 1}

Fig. 2 exhibits solid-state ${ }^{29} \mathrm{Si}$ and ${ }^{13} \mathrm{C}$ NMR spectra of Pb-IIMS. As seen from Fig. 2(a), the typical peaks at about $-109.0,-100.7 \mathrm{ppm}$ can be attributed to $\mathrm{Q}^{4}\left[\mathrm{Si}(\mathrm{OSi})_{4}\right.$, siloxane], $\mathrm{Q}^{3}\left[\mathrm{Si}(\mathrm{OH})(\mathrm{OSi})_{3}\right.$, single silanol] which are highly comprehensible to two types of the framework crosslinking on mesoporous silica. The peak at $-57.3,-16.3$ ppm are assigned to $\mathrm{T}^{3}\left[\mathrm{SiR}(\mathrm{OSi})_{3}\right]$ organosilicon, and $\mathrm{D}^{2}$ ethyl silane of silylating agents, respectively [42-44]. Fig. 2(b) shows the characteristic band of $\mathrm{C}=\mathrm{O}$ at 201.4 ppm, and the peak near 59.9, 42.6, 23.6 ppm belonged to carbon atom of silica chain; 
the characteristic carbon peaks of benzene were found at 122.0, 129.0, 118.9, 161.7 ppm; methyne carbon was near $77.6 \mathrm{ppm}$. These results confirm that the functional monomer DPP is covalently anchored to the surface of mesoporous silica.

\section{Fig. 2}

SEM results (Fig. 3) show the Pb-IIMS particles are packing regularly, moreover, the surface of $\mathrm{Pb}$-IIMS become tough which is likely to the formation of functionalization on the surface of mesoporous silicas. TEM images (Fig. 4) demonstrated that $\mathrm{Pb}$-IIMS-SBA-15, Pb-IIMS-MCM-41 are a clear arrangement of hexagonal pores with channel-like structures running parallel, and Pb-IIMS-FDU-12 with spherical mesopores arranged in cubic structure, which provide the evidence that IIMS materials well preserved the structures of SBA-15, MCM-41, FDU-12 after functionalization [45-47].

\section{Fig. 3}

\section{Fig. 4}

The elements on the surface of Pb-IIMS were studied by energy dispersive X-ray (EDX). As shown in Fig. 5, we can clearly observe the presence of $\mathrm{C}, \mathrm{N}, \mathrm{O}$ and $\mathrm{Si}$, which further demonstrate the functional monomer successfully modified on mesoporous silicas. Compared with Pb-IIMS-SBA-15 and Pb-IIMS-FDU-12, $\mathrm{Pb}$-IIMS-MCM-41 possessed higher percentage of nitrogen indicating that more functional monomers were grafted on MCM-41. The absence of $\mathrm{Pb}$ (II) in $\mathrm{EDX}$ spectrum confirm complete elution of $\mathrm{Pb}$ (II) from IIMS.

The nitrogen adsorption-desorption isotherm and distribution of pore size are shown in Fig. 6, indicating isotherms of Pb-IIMS-SBA-15, Pb-IIMS-MCM-41 and Pb-IIMS-FDU-12 were typical type IV with H1 [31], H1 [48] and H2 [49] hysteresis loop. Compared with SBA-15, MCM-41 and FDU-12, the volumes of our prepared adsorbents reduced and hysteresis loops shifted to lower relative pressure after 
loading, which suggested that the pore size of mesoporous had decreased. Moreover, the decrease of the pore size after modification can be clearly seen from the pore size distribution curves. These changes were indicative that the functional monomer had successfully grafted on the channel of SBA-15, MCM-41, FDU-12.

Fig. 5

Fig. 6

The small angel XRD results are shown in Fig. 7, which exhibited well-recorded peaks in the range of $2 \theta=0.7-2.0^{\circ}, 2 \theta=2.08^{\circ}, 2 \theta=0.6-1.5^{\circ}$ for Pb-IIMS-SBA-15, Pb-IIMS-MCM-41, Pb-IIMS-FDU-12 respectively, which could be indexed to (100), (110) and (200) reflections of SBA-15 [50,51], (100) reflection of MCM-41 [52], (311) and (400) reflections of FDU-12 [47]. These details suggested that the structure of SBA-15, MCM-41, FDU-12 were well preserved, which well supported the results of SEM and TEM. Compared with original mesoporous, there was obvious reduce in diffraction peak of Pb-IIMS-SBA-15, Pb-IIMS-MCM-41, Pb-IIMS-FDU-12 testified $\mathrm{Pb}$ (II) ion-imprinted polymers have coated inside mesoporous channels, since the sticking of organic functional monomer to mesoporous channels can decrease the scattering power of mesoporous silicate wall [53].

Fig. 7

\subsection{Adsorption performances}

\subsubsection{Effect of $p H$}

The $\mathrm{pH}$ volumes of solutions are the most important parameter affecting the adsorption capacity of adsorbents, as $\mathrm{pH}$ influences protonation of coordination sites of heavy metal ions grafted on mesoporous silica. The relationship between extraction efficiency of $\mathrm{Pb}(\mathrm{II})$ and various $\mathrm{pH}$ values of solutions were presented in Fig. 8. It 
was clear that the effect of solution $\mathrm{pH}$ on adsorption capacity is significant. This graph displayed a maximum extraction efficiency of Pb-IIMS-SBA-15, Pb-IIMS-MCM-41, Pb-IIMS-FDU-12 near $\mathrm{pH}$ 6.0. The extraction efficiency kept increasing from $\mathrm{pH} 2.0$ to 6.0, and then the increase of $\mathrm{pH}$ had no obvious effect on extraction efficiency of sorbents. So the optimal $\mathrm{pH}$ values of Pb-IIMS-SBA-15, Pb-IIMS-MCM-41, Pb-IIMS-FDU-12 were determined to be $\mathrm{pH}$ 6.0. This phenomenon may due to the degree of protonation of bis-pyrazolyl group gradually decrease with increasing of $\mathrm{pH}$ values, resulting in $\mathrm{Pb}$-IIMS more easily adsorbed $\mathrm{Pb}(\mathrm{II})$ in the solution $[14,19]$.

\section{Fig. 8}

\subsubsection{Choice of elution}

Series of acidic elution solutions such as $\mathrm{HNO}_{3}, \mathrm{HCl}$, at different concentrations and their mixture with thiourea as an auxiliary ligand [54] were used to explore the elution efficiency of $\mathrm{Pb}(\mathrm{II})$ ions from ion-imprinted materials. As Table 1 shown, optimal quantitative percentage of recovery of $\mathrm{Pb}$ (II) could be obtained with $10 \mathrm{~mL}$ of $\mathrm{HCl}$ (3 mol $\mathrm{L}^{-1}$ ). The percentage of recoveries of Pb-IIMS-SBA-15, Pb-IIMS-MCM-41, Pb-IIMS-FDU-12 are $95.9 \%, 96.7 \%$ and $93.9 \%$, partly.

Table 1 Effect of diverse types and concentrations of stripping agents. ${ }^{\text {a }}$

\begin{tabular}{|c|c|c|c|c|}
\hline \multirow{2}{*}{ Stripping agent } & \multicolumn{4}{|c|}{$\mathrm{R}^{\mathrm{b}}(\%) \pm \mathrm{S}^{\mathrm{c}}(\%)$} \\
\hline & $\left(\mathrm{mol} \mathrm{L}^{-1}\right)$ & Pb-IIMS-SBA-15 & Pb-IIMS-MCM-41 & Pb-IIMS-FDU-12 \\
\hline $\mathrm{HNO}_{3}$ & 1 & $87.5 \pm 0.9$ & $91.1 \pm 0.5$ & $84.7 \pm 1.5$ \\
\hline $\mathrm{HCl}$ & 1 & $92.7 \pm 1.0$ & $92.5 \pm 0.9$ & $89.9 \pm 1.3$ \\
\hline $\mathrm{HNO}_{3}$ & 3 & $90.6 \pm 1.5$ & $93.1 \pm 0.7$ & $90.1 \pm 0.7$ \\
\hline $\mathrm{HCl}$ & 3 & $95.9 \pm 0.5$ & $96.7 \pm 0.7$ & $93.9 \pm 1.0$ \\
\hline $\mathrm{HNO}_{3}+$ thiourea & $1 / 1$ & $85.3 \pm 0.5$ & $89.4 \pm 1.1$ & $84.3 \pm 0.4$ \\
\hline $\mathrm{HCl}+$ thiourea & $1 / 1$ & $90.1 \pm 0.6$ & $90.8 \pm 1.6$ & $88.4 \pm 0.9$ \\
\hline
\end{tabular}


${ }^{\mathrm{a}}$ The volumes of stripping agents are all $10 \mathrm{~mL}$.

${ }^{\mathrm{b}}$ Recovery

${ }^{\mathrm{c}}$ Standard deviation

\subsubsection{Adsorption and kinetic studies}

The adsorption isotherms of IIMS and NIMS towards $\mathrm{Pb}$ (II) ions at $25{ }^{\circ} \mathrm{C}$ were shown in Fig. 9. It could be observed that the adsorption capacity of $\mathrm{Pb}$ (II) increased fast with increasing initial concentrations of $\mathrm{Pb}(\mathrm{II})$, until the Pb-IIMS-SBA-15, $\mathrm{Pb}$-IIMS-MCM-41, and Pb-IIMS-FDU-12 reached saturation adsorption capacity (193.2, 283.7 and $155.2 \mathrm{mg} \mathrm{g}^{-1}$, respectively) when the concentrations of $\mathrm{Pb}$ (II) were near 50, 70 and $40 \mathrm{ppm}$, respectively. Compared with their corresponding NIMS, the adsorption capacity of IIMS were higher, indicating the recognition sites of $\mathrm{Pb}$ (II) modified on IIMS with higher affinity. Furthermore, the Pb-IIMS-MCM-41 possessed better binding ability than that of Pb-IIMS-SBA-15, Pb-IIMS-FDU-12, which was well corresponding to results of EDX that Pb-IIMS-MCM-41 was modified more functional monomer.

The adsorption isotherm experiments can contribute to understand the adsorption characters of Pb-IIMS. The Langmuir and Freundlich models were employed to study the adsorbate-adsorbent interactions. Langmuir model, which assumed that the adsorption sites grafted on the surface of adsorbent are homogeneous, causing the monolayer adsorption of adsorbate [55,56]. The Langmuir equation was expressed as:

$\frac{\mathrm{C}_{\mathrm{e}}}{\mathrm{q}_{\mathrm{e}}}=\frac{\mathrm{C}_{\mathrm{e}}}{\mathrm{q}_{\mathrm{m}}}+\frac{1}{\mathrm{bq}_{\mathrm{m}}}$

where $\mathrm{q}_{\mathrm{e}}\left(\mathrm{mg} \mathrm{g}^{-1}\right)$ and $\mathrm{C}_{\mathrm{e}}\left(\mathrm{mg} \mathrm{L}^{-1}\right)$ are the adsorption capacity and concentration of $\mathrm{Pb}$ (II) in solution, $\mathrm{q}_{\mathrm{m}}\left(\mathrm{mg} \mathrm{g}^{-1}\right)$ is the maximum adsorption capacity of adsorbent, $\mathrm{b}(\mathrm{L}$ $\mathrm{mg}^{-1}$ ) is the Langmuir constant.

The Freundlich model describes the multilayer adsorption and the heterogeneous system [57]. The equation of Freundlich was defined as:

$\mathrm{q}_{\mathrm{e}}=\mathrm{K}_{\mathrm{f}} \mathrm{C}_{\mathrm{e}}^{1 / \mathrm{n}}$ 
$\ln \mathrm{q}_{\mathrm{e}}=\frac{1}{\mathrm{n}} \ln \mathrm{C}_{\mathrm{e}}+\ln \mathrm{K}_{\mathrm{f}}$

Where $\mathrm{K}_{\mathrm{f}}\left(\left(\mathrm{mg} \mathrm{g}^{-1}\right)\left(\mathrm{L} \mathrm{mol}^{-1}\right)^{1 / \mathrm{n}}\right)$ and $\mathrm{n}$ are the constants of Freundlich, which correlate adsorption capacity and adsorption intensity, respectively.

The constants of Langmuir and Freundlich models were summarized in Table 2. For Pb-IIMS-SBA-15， Pb-IIMS-MCM-41 and Pb-IIMS-FDU-12, the correlation coefficients got from Langmuir model $\left(R^{2}=0.9932,0.9928,0.9699\right)$ were higher than that of Freundlich model $\left(\mathrm{R}^{2}=0.6674,0.4609,0.2758\right)$, indicating that Langmuir model showed better fit and the adsorption of IIMS for $\mathrm{Pb}(\mathrm{II})$ take place at a monolayer coverage of adsorbents surface. The maximum adsorption capacity of $\mathrm{Pb}$-IIMS-MCM-41 obtained from Langmuir model is $344.8 \mathrm{mg} \mathrm{g}^{-1}$, which is higher than previously reported $\mathrm{Pb}$ (II) ion-imprinted adsorbents. (Listed in Table 3).

Fig. 9

The influence of contact time between adsorbents and $\mathrm{Pb}(\mathrm{II})$ were carried out to judge adsorption kinetics, results were displayed in Fig. 9. (c). It can be seen that the adsorption capacity of adsorbents increased sharply during the initial stage. Adsorption of Pb-IIMS-SBA-15, Pb-IIMS-MCM-41, Pb-IIMS-FDU-12 reached equilibrium within 40, 20, 40 min, respectively. Excitedly, Pb-IIMS-MCM-41 presented not only faster adsorption rate to $\mathrm{Pb}$ (II) than that of other two adsorbents, but higher equilibrium adsorption capacity within $20 \mathrm{~min}$.

Table 2 Langmuir and Freundlich isotherm constants of IIMS for the adsorption of $\mathrm{Pb}(\mathrm{II})$

\begin{tabular}{|c|c|c|c|}
\hline \multicolumn{4}{|c|}{ Langmuir isotherm constants } \\
\hline Adsorbent & $\mathrm{q}_{\mathrm{m}}\left(\mathrm{mg} \mathrm{g}^{-1}\right)$ & $\mathrm{b}\left(\mathrm{L} \mathrm{mg}^{-1}\right)$ & $\mathrm{R}^{2}$ \\
\hline Pb-IIMS-SBA-15 & 211.4 & 2.3107 & 0.9932 \\
\hline Pb-IIMS-MCM-41 & 344.8 & 2.3499 & 0.9928 \\
\hline Pb-IIMS-FDU-12 & 178.5 & 0.7763 & 0.9699 \\
\hline \multicolumn{4}{|c|}{ Freundlich isotherm constants } \\
\hline Adsorbent & $\mathrm{K}_{\mathrm{f}}\left(\left(\mathrm{mg} \mathrm{g}^{-1}\right)\left(\mathrm{Lmol}^{-1}\right)^{1 / \mathrm{n}}\right)$ & $\mathrm{N}$ & $\mathrm{R}^{2}$ \\
\hline Pb-IIMS-SBA-15 & 128.8 & 5.441 & 0.6674 \\
\hline
\end{tabular}




\begin{tabular}{cccc}
\hline Pb-IIMS-MCM-41 & 172.3 & 3.833 & 0.4609 \\
$\mathrm{~Pb}-\mathrm{IIMS}-F D U-12$ & 93.2 & 6.707 & 0.2758 \\
\hline
\end{tabular}

Table 3 Comparison of maximum adsorption capacity between Pb-IIMS-MCM-41 and the reported adsorbents towards $\mathrm{Pb}(\mathrm{II})$

\begin{tabular}{lcc}
\hline \multicolumn{1}{c}{ Adsorbent } & $\mathrm{q}_{\mathrm{m}}\left(\mathrm{mg} \mathrm{g}^{-1}, \mathrm{~Pb}(\mathrm{II})\right)$ & Reference \\
\hline Chitosan grafted on SBA-15 & 38.01 & 58 \\
Chitosan modified on SBA-15 & 42.55 & 14 \\
iminodiacetic acid on support matrix of SBA-15 & 160 & 31 \\
Hexadecyltrimethyl ammoniumbromide functionalized & 57.74 & 29 \\
on MCM-41 & & \\
Chitosan beads & 72.89 & 59 \\
4-VP and acrylate-moded spirulina platensis magnetic & 136.6 & 60 \\
ion-imprinted polymer & & \\
triethylene-tetramine grafted magnetic chitosan & 370.63 & 61 \\
Amino siloxane oligomer-linked graphene oxide & 312.5 & 62 \\
Pb-IIMS-MCM-41 & 344.8 & this work \\
\hline
\end{tabular}

To investigate the mechanism of adsorption of $\mathrm{Pb}(\mathrm{II})$, the adsorption kinetics were further analyzed by using different kinetic models containing the pseudo-first-order (eq. 9) and pseudo-second-order (eq. 10) [63].

$\ln \left(\mathrm{q}_{\mathrm{e}}-\mathrm{q}_{\mathrm{t}}\right)=\ln \mathrm{q}_{\mathrm{e}}-\mathrm{K}_{1} \mathrm{t}$

$\frac{1}{q_{t}}=\frac{1}{k_{2} q_{e}^{2}}+\frac{t}{q_{e}}$

Where $\mathrm{q}_{\mathrm{e}}$ and $\mathrm{q}_{\mathrm{t}}\left(\mathrm{mg} \mathrm{g}^{-1}\right)$ are the amounts of adsorbed $\mathrm{Pb}(\mathrm{II})$ per mass of sorbent at equilibrium conditions and at time $\mathrm{t}$, respectively. $\mathrm{k}_{1}\left(\mathrm{~min}^{-1}\right)$ and $\mathrm{k}_{2}\left(\mathrm{~g} \mathrm{mg}^{-1} \mathrm{~min}^{-1}\right)$ are the rate constant of pseudo-first-order and pseudo-second -order, respectively. The kinetic constants and correlation coefficients are calculated and summed up in Table 4. The correlation coefficients of Pb-IIMS-SBA-15, Pb-IIMS-MCM-41, and Pb-IIMS-FDU-12 obtained from pseudo-second-order $\left(\mathrm{R}^{2}=0.9691,0.9992\right.$, and $0.9735)$ greater than that of pseudo-first-order $\left(\mathrm{R}^{2}=0.9567,0.7090\right.$, and 0.7829$)$. Hence, the adsorption processes of IIMS for $\mathrm{Pb}$ (II) follow the pseudo-second-order model better, which can be accessed as chemical reaction between adsorbents and $\mathrm{Pb}$ (II) ion [64]. The adsorption rate could be dominated by chemical adsorption 
through election exchange between adsorbent and $\mathrm{Pb}(\mathrm{II})$ [65].

According to above analysis, the reasons of considerable adsorption performance results could be explained from the following aspects. First, the traditional adsorbents show poor site accessibility, may owe to adsorption sites are embedded with high density of cross-linked polymer matrix [14]. Second, metal ion-imprint mesoporous silica solves the disadvantage of traditional adsorbents [31], abundant $\mathrm{Si}-\mathrm{OH}$ on the surface of mesoporous silica could provide more modification sites to graft more functional monomers. Third, our gained bidentate functional group containing $\mathrm{N}$ can easily react to $\mathrm{Pb}(\mathrm{II})$. Consequently, a large number of adsorption sites grafted on the surface of IIMS could own high adsorption capacity and fast adsorption rate.

Table 4 Kinetics parameters of pseudo-fiirst and pseudo-second order for adsorbents.

\begin{tabular}{lcccc|ccc}
\hline & \multicolumn{3}{c|}{ pseudo-first-order } & \multicolumn{3}{c}{ pseudo-second-order } \\
\cline { 2 - 9 } Adsorbent & $\begin{array}{c}\text { exptl } \mathrm{q}_{\mathrm{e}} \\
\left(\mathrm{mg} \mathrm{g}^{-1}\right)\end{array}$ & $\begin{array}{c}\mathrm{K}_{1} \\
\left(\mathrm{~min}^{-1}\right)\end{array}$ & $\begin{array}{c}\mathrm{q}_{\mathrm{e}} \\
\left(\mathrm{mg} \mathrm{g}^{-1}\right)\end{array}$ & $\mathrm{R}^{2}$ & $\begin{array}{c}\mathrm{K}_{2} \\
\left(\mathrm{~min}^{-1}\right)\end{array}$ & $\begin{array}{c}\mathrm{q}_{\mathrm{e}} \\
\left(\mathrm{mg} \mathrm{g}^{-1}\right)\end{array}$ & $\mathrm{R}^{2}$ \\
\hline Pb-IIMS-SBA-15 & 193.2 & 0.1026 & 298.2 & 0.9567 & $1.09 \times 10^{-3}$ & 204.1 & 0.9691 \\
\hline $\mathrm{Pb}-I I M S-M C M-41$ & 283.7 & 0.0540 & 38.98 & 0.7090 & $5.59 \times 10^{-3}$ & 285.7 & 0.9992 \\
\hline Pb-IIMS-FDU-12 & 155.2 & 0.0438 & 107.1 & 0.7829 & $2.60 \times 10^{-4}$ & 200.0 & 0.9735 \\
\hline
\end{tabular}

\subsection{Selectivity studies}

\subsubsection{Selective adsorption experiments}

Adsorption selectivity and anti-influence were both studied, as selectivity is the essence to assess the adsorption performance of IIMS to $\mathrm{Pb}$ (II). Adsorption selectivity examinations toward $\mathrm{Pb}(\mathrm{II})$ were carried out in presence of $\mathrm{Cd}(\mathrm{II}), \mathrm{Co}(\mathrm{II}), \mathrm{Cu}(\mathrm{II})$, $\mathrm{Hg}(\mathrm{II}), \mathrm{Mg}(\mathrm{II}), \mathrm{Mn}(\mathrm{II})$, and $\mathrm{Zn}(\mathrm{II})$ at optimal conditions of three kinds of adsorbents, the concentrations were same as $\mathrm{Pb}(\mathrm{II})\left(10 \mathrm{mg} \mathrm{L}^{-1}\right)$. The selectivity coefficient $(\alpha)$ and relative selectivity coefficient $(\beta)$ are summarized in Table 5. As can be seen from the Fig. 10, Pb-IIMS-SBA-15, Pb-IIMS-MCM-41 and Pb-IIMS-FDU-12 presented commendable adsorption selectivity for $\mathrm{Pb}(\mathrm{II})$ containing competitive metal ions. More concretely, Table 5 clearly shows that selectivity coefficients of $\mathrm{Pb}$-IIMS-MCM-41 for $\mathrm{Pb}(\mathrm{II})$ with respect to competitive metal ions were higher than 
that of the other two adsorbents. Moreover, the selectivity coefficients of Pb-IIMS-MCM-41 for $\mathrm{Pb}(\mathrm{II}) / \mathrm{Cd}(\mathrm{II}), \mathrm{Pb}(\mathrm{II}) / \mathrm{Mg}(\mathrm{II})$ and $\mathrm{Pb}(\mathrm{II}) / \mathrm{Zn}(\mathrm{II})$ were 132.68 , 576.61 and 104.25 respectively, while selectivity coefficients of DPP@MCM-41 are only $7.13,6.95$ and 5.86 . It could be concluded that the ion-imprinting dramatically increase the selectivity to the template ion due to the formation of 3-D recognition sites inside the Pb-IIMS [11,58]. Meanwhile, Pb-IIMS-MCM-41 shown the best selectivity which can be explained as follow. From the results of EDX, $\mathrm{Pb}$-IIMS-MCM-41 possessed the highest percentage of nitrogen indicating that more functional monomers were grafted on MCM-41, so we can conclude that the most recognition sites for $\mathrm{Pb}(\mathrm{II})$ formed on $\mathrm{Pb}$-IIMS-MCM-41 which results in the best selectivity.

\section{Fig. 10}

Table 5 Selective adsorption performance of IIMS and NIMS

\begin{tabular}{|c|c|c|c|c|c|c|c|c|c|}
\hline \multirow{3}{*}{$\begin{array}{c}\text { Metal } \\
\text { ions }\end{array}$} & \multicolumn{6}{|c|}{ Selectivity coefficient $(\alpha)$} & \multicolumn{3}{|c|}{$\begin{array}{c}\text { Relative selectivity } \\
\text { coefficient }(\beta)\end{array}$} \\
\hline & Pb-IIMS & Pb-IIMS & Pb-IIMS & DPP@ & DPP@ & DPP@ & SBA- & MCM & FDU- \\
\hline & -SBA-15 & -MCM-41 & -FDU-12 & SBA-15 & MCM-41 & FDU-12 & 15 & -41 & 12 \\
\hline $\mathrm{Cd}(\mathrm{II})$ & 61.12 & 132.68 & 8.89 & 3.61 & 7.13 & 2.58 & 16.93 & 18.61 & 3.45 \\
\hline $\mathrm{Co}(\mathrm{II})$ & 19.79 & 38.76 & 5.23 & 2.60 & 4.53 & 2.05 & 7.60 & 8.56 & 2.55 \\
\hline $\mathrm{Cu}(\mathrm{II})$ & 32.83 & 63.13 & 4.07 & 1.00 & 1.68 & 0.71 & 32.70 & 37.62 & 5.73 \\
\hline $\mathrm{Hg}(\mathrm{II})$ & 21.21 & 44.77 & 3.79 & 0.81 & 1.08 & 0.41 & 26.19 & 41.54 & 9.37 \\
\hline $\operatorname{Mg}(\mathrm{II})$ & 158.48 & 576.61 & 26.34 & 3.36 & 6.95 & 2.86 & 47.10 & 82.81 & 9.22 \\
\hline $\operatorname{Mn}(\mathrm{II})$ & 22.10 & 63.07 & 7.15 & 2.5 & 7.98 & 2.45 & 8.82 & 7.90 & 2.92 \\
\hline $\mathrm{Pb}(\mathrm{II})$ & 1 & 1 & 1 & 1 & 1 & 1 & 1 & 1 & 1 \\
\hline $\mathrm{Zn}(\mathrm{II})$ & 59.54 & 104.25 & 13.18 & 3.74 & 5.86 & 4.40 & 15.91 & 17.78 & 2.99 \\
\hline
\end{tabular}

\subsubsection{Effect of the Interfering Ions}

To evaluate the possibility of application of adsorbents, the influences of various ions exist in water such as $\mathrm{Li}(\mathrm{I}), \mathrm{Na}(\mathrm{I}), \mathrm{K}(\mathrm{I}), \mathrm{Mg}(\mathrm{II}), \mathrm{Mn}$ (II), $\mathrm{Co}(\mathrm{II}), \mathrm{Cd}(\mathrm{II}), \mathrm{Cr}(\mathrm{III}), \mathrm{Cu}(\mathrm{II})$, $\mathrm{Cl}^{-}, \mathrm{SO}_{4}{ }^{2-}, \mathrm{CH}_{3} \mathrm{COO}^{-}, \mathrm{NH}_{4}{ }^{+}$were studied. We used tolerable limit to defined the maximum concentration of foreign ions that could cause an error less than $\pm 5 \%$ in the 
absence of interference, the tolerable concentration ratio was used $\mathrm{X} / \mathrm{Pb}$ (II) to indicate. The results are presented in Table 6. From the sheet, it can be seen that the foreign ions have no significant effects on detection of $\mathrm{Pb}(\mathrm{II})$ ion for NIMS at their optimal conditions, respectively.

Table 6 The tolerance ratio of various ions on the determination of $\mathrm{Pb}(\mathrm{II})$ ions

\begin{tabular}{|c|c|c|c|c|}
\hline \multirow[b]{2}{*}{$\begin{array}{c}\text { Interference } \\
\text { ions } \\
\text { (X) }\end{array}$} & \multirow[b]{2}{*}{$\begin{array}{c}\text { Tolerable } \\
\text { concentration } \\
\text { ratio } \mathrm{X} / \mathrm{Pb}(\mathrm{II})\end{array}$} & \multicolumn{3}{|c|}{ Extraction $\%$} \\
\hline & & Pb-IIMS-SBA-15 & Pb-IIMS-MCM-41 & Pb-IIMS-FDU-12 \\
\hline $\mathrm{Li}^{+}$ & 1000 & 94.3 & 96.3 & 93.5 \\
\hline $\mathrm{Na}^{+}$ & 1000 & 95.3 & 93.3 & 94.3 \\
\hline $\mathrm{K}^{+}$ & 1000 & 91.4 & 94.1 & 92.8 \\
\hline $\mathrm{Mg}^{2+}$ & 1000 & 97.1 & 93.8 & 95.2 \\
\hline $\mathrm{Mn}^{2+}$ & 1000 & 96.4 & 92.5 & 95.8 \\
\hline $\mathrm{Co}^{2+}$ & 1000 & 98.4 & 93.6 & 96.4 \\
\hline $\mathrm{Cd}^{2+}$ & 1000 & 94.1 & 94.7 & 95.7 \\
\hline $\mathrm{Ba}^{2+}$ & 1000 & 97.2 & 95.2 & 96.2 \\
\hline $\mathrm{Hg}^{2+}$ & 50 & 92.8 & 93.7 & 93.5 \\
\hline $\mathrm{Cr}^{3+}$ & 1000 & 96.1 & 94.9 & 94.3 \\
\hline $\mathrm{Cu}^{2+}$ & 1000 & 96.5 & 95.6 & 95.1 \\
\hline $\mathrm{Cl}^{-}$ & 1000 & 99.5 & 99.9 & 98.5 \\
\hline $\mathrm{SO}_{4}{ }^{2-}$ & 1000 & 98.6 & 96.0 & 95.6 \\
\hline \multirow[t]{3}{*}{$\mathrm{CH}_{3} \mathrm{COO}^{-}$} & 800 & 54.9 & 99.7 & 48.3 \\
\hline & 600 & 99.6 & 99.8 & 74.8 \\
\hline & 400 & 98.9 & 99.6 & 94.5 \\
\hline \multirow[t]{2}{*}{$\mathrm{NH}_{4}^{+}$} & 1000 & 95.17 & 96.04 & 65.62 \\
\hline & 700 & 97.91 & 98.38 & 96.75 \\
\hline
\end{tabular}

\subsection{Reusability of Pb-IIMS-MCM-41}

Other than selectivity, reusability is an important factor as well in application of IIMS. 
Considering adsorption capacity, adsorption kinetic, selectivity and anti-interference of three kinds of adsorbents, we chose Pb-IIMS-MCM-41 as optimal adsorbent to investigate the reusability. The stability and reusability of Pb-IIMS-MCM-41 was reused for five adsorption-desorption cycles by using $3 \mathrm{~mol} \mathrm{~L}^{-1} \mathrm{HCl}$ as desorption medium, the results are displayed in Fig. 11. In addition to a slight decrease in extraction efficiency during twelve cycles, the ion-imprinted mesoporous silica still keep over $95.0 \%$ extraction efficiency for $\mathrm{Pb}(\mathrm{II})$. Consequently, the obtained IIMS were demonstrated to be reused with excellent extraction efficiency.

\section{Fig. 11}

\subsection{The application of Pb-IIMS-MCM-41 packed SPE column} $(P b-I I M S-M C M-41-S P E)$

\subsubsection{Optimal conditions}

As the outstanding selectivity and reusability, Pb-IIMS-MCM-41 were applied as filling material to prepare SPE column for the removal and determination of $\mathrm{Pb}(\mathrm{II})$ in tap and river water. The flow rates of loading sample and the elution are critical parameters dominating the adsorption amount, analytical time and SPE recoveries. To obtain the optimal extraction recoveries, the effect of flow rate of the standard $\mathrm{Pb}$ (II) solution $\left(5 \mathrm{~mL}, 50 \mu \mathrm{g} \mathrm{L}^{-1}\right)$ on the adsorption of $\mathrm{Pb}(\mathrm{II})$ was studied in the range of 0.2-2.0 $\mathrm{mL} \mathrm{min}^{-1}$ at $\mathrm{pH}$ 6.0. Generally speaking, the $\mathrm{Pb}(\mathrm{II})$ could be adsorbed quantitatively by $\mathrm{Pb}$-IIMS-MCM-41 with the efficiency above 95\% during the flow rate of 0.2-0.7 $\mathrm{mL} \mathrm{min}^{-1}$. However, the adsorption efficiency decreased to below $95.0 \%$ at the sample flow rate above $0.7 \mathrm{~mL} \mathrm{~min}^{-1}$, which may well due to the reduction of the contact time between $\mathrm{Pb}(\mathrm{II})$ and the packing material with increasing of flow rate. So, a flow rate of $0.5 \mathrm{~mL} \mathrm{~min}^{-1}$ was chosen as optimal sample rate. On the other hand, elution $(2.5 \mathrm{~mL}, 3 \mathrm{~mol} / \mathrm{L} \mathrm{HCl})$ flow rates varying from 0.2 to $2 \mathrm{~mL} \mathrm{~min}^{-1}$ were studied to find the optimal SPE recoveries. Finally, the flow rate of $0.5 \mathrm{~mL} \mathrm{~min}^{-1}$ was carried out for elution. 


\subsubsection{Analytical performance and application in water samples}

The analytical performances based on Pb-IIMS-MCM-41-SPE were investigated under the optimized conditions. An excellent linear relationship was presented in the range of $0.5-50 \mu \mathrm{g} \mathrm{L}^{-1}$, with a linear equation of $\mathrm{y}=0.9903 \mathrm{x}-0.0971,\left(\mathrm{R}^{2}=0.9998\right)$. The limit detection (LOD) of $0.015 \mu \mathrm{g} \mathrm{L}^{-1}$ for $\mathrm{Pb}$ (II) was calculated as $3 \mathrm{SD} / \mathrm{m}$, where SD is the standard deviation of nine replicate blank extraction divided by blank extraction and $\mathrm{m}$ is the slope of the calibration curve. The extraction precisions of $\mathrm{Pb}$-IIMS-MCM-41-SPE at 10 and $50 \mu \mathrm{g} \mathrm{L}^{-1}$ were assessed in the forms of relative standard deviation (RSD), which were achieved $3.5 \%$ and $1.9 \%$ respectively. In addition, the Pb-IIMS-MCM-41-SPE was used for the determination of trace $\mathrm{Pb}(\mathrm{II})$ in tap and river water samples to access the applicability of the developed method. The recoveries were conducted with the standard addition method by spiking two different concentrations of $\mathrm{Pb}$ (II) $\left(5\right.$ and $\left.10 \mu \mathrm{g} \mathrm{L}^{-1}\right)$ with the pretreatment tap and river water, respectively, each sample was analyzed three replicates. As listed in Table 7, the analytical recoveries in the range of $98.3 \%$ - $101.4 \%$, with the RSD varying from $2.0 \%$ to $1.2 \%$. which can be inferred that Pb-IIMS-MCM-41 is a desired candidate for SPE adsorbent.

Table 7 Recoveries (\%) and Relative standard deviations (RSD, \%) of Pb-IIMS-MCM-41-SPE for $\mathrm{Pb}$ (II) obtained from water samples.

\begin{tabular}{cccc}
\hline Sample & added $\left(\operatorname{ug~L}{ }^{-1}\right)$ & Found $\left(\mathrm{ug} \mathrm{L}^{-1}\right)$ & Recovery \pm RSD $(\%)$ \\
\hline tap water & 0 & $14.377 \pm 0.382$ & - \\
& 5 & $19.447 \pm 0.577$ & $101.4 \% \pm 1.3 \%$ \\
Huangpu river water & 10 & $24.203 \pm 0.625$ & $98.3 \% \pm 2.0 \%$ \\
& 0 & $30.705 \pm 0.465$ & - \\
& 5 & $35.663 \pm 0.735$ & $99.2 \% \pm 1.5 \%$ \\
& 10 & $40.849 \pm 0.628$ & $101.4 \% \pm 1.2 \%$ \\
\hline
\end{tabular}

\section{Conclusions}

$\mathrm{Pb}$ (II) ion-imprinted mesoporous silica materials modified with bis-pyrazolyl group were successfully prepared. Adsorption experiments for $\mathrm{Pb}(\mathrm{II})$ indicated that these ion-imprinted materials possess good chemical stability, considerable adsorption 
capacity, and do exhibit improved selectivity as compared to the corresponding non-imprinted materials. $\mathrm{Pb}(\mathrm{II})$ ion-imprinted material $\mathrm{Pb}$-IIMS-MCM-41 performed excellent adsorption performance and outstanding reusability, and could be employed as filling adsorbent of solid-phase extraction column. These results demonstrated that $\mathrm{Pb}$ (II) ion-imprinted material $\mathrm{Pb}$-IIMS-MCM-41 is promising solid-phase extraction adsorbent for removal, preconcentration and detection of $\mathrm{Pb}(\mathrm{II})$ in water.

\section{Acknowledgements}

Financial support by the National Science Foundation of China (grant nos. 20971026, 21271047), General Administration of Quality Supervision, Inspection and Quarantine of China (Nos. 2015IK217) and Inspection and Quarantine Public Benefit Research Foundation (Nos. 201310065) is gratefully acknowledged.

\section{References}

[1] M.E. Mahmoud, M.M. Osman, O.F. Hafez, E. Elmelegy, J. Hazard. Mater. 173 (2010) 349-357.

[2] J. Gong, X. Wang, X. Shao, S. Yuan, C. Yang, X. Hu, Talanta 101 (2012) 45-52.

[3] D.C. Bellinger, A.M. Bellinger, J. Clin. Invest. 116 (2006) 853-857.

[4] A. Dąbrowski, Z. Hubicki, P. Podkościelny, E. Robens, Chemosphere 56 (2004) 91-106.

[5] L.D. Palma, P. Ferrantelli, C. Merli, F. Biancifiori, J. Hazard. Mater. B 103 (2003) 153-168.

[6] A. Demirbas, J. Hazard. Mater. 157 (2008) 220-229.

[7] W.S.W. Ngah, M.A.K.M. Hanafiah, Bioresour. Technol. 99 (2008) 3935-3948.

[8] P.E. Hande, A.B. Samui, P.S. Kulkarni, Environ. Sci. Pollut. Res. 22 (2015) 7375-7404.

[9] M. Behbahani, A. Bagheri, M. Taghizadeh, M. Salarian, O. Sadeghi, L. Adlnasab, K. Jalali, Food Chemistry 138 (2013) 2050-2056.

[10] P.E. Hande, S. Kamble, A.B. Samui, P.S. Kulkarni, Ind. Eng. Chem. Res. 55 (2016) 3668-3678.

[11] X. Cai, J. Li, Z. Zhang, F. Yang, R. Dong, L. Chen, ACS Appl. Mater. Interfaces. 6 (2014) 305-313.

[12] M.K. Bojdi, M.H. Mashhadizadeh, M. Behbahani, A. Farahani, S.S.H. Davarani, A. Bagheri, Electrochim. Acta 136 (2014) 59-65.

[13] M. Behbahani, P.G. Hassanlou, M.M. Amini, H.R. Moazami, H.S. Abandansari, A. Bagheri, S.H. Zadeh, Food Anal. Methods 8 (2015) 558-568. 
[14] Y. Liu, Z. Liu, J. Gao, J. Dai, J. Han, Y. Wang, J. Xie, Y. Yan, J. Hazard. Mater. 186 (2011) 197-205.

[15] H. Ge, T. Hua, X. Chen, J. Hazard. Mater. 308 (2016) 225-232.

[16] S. Sun, L. Wang, A. Wang, J. Hazard. Mater. B 136 (2006) 930-937.

[17] H.T. Fan, X.T. Sun, Z.G. Zhang, W.X. Li, J. Chem. Eng. Data 59 (2014) $2106-2114$.

[18] X. Zhu, Y. Cui, X. Chang, X. Zou, Z. Li, Microchim. Acta 164 (2009) 125-132.

[19] M. Zhang, Z. Zhang, Y. Liu, X. Yang, L. Luo, J. Chen, S. Yao, Chem. Eng. J. 178 (2011) 443- 450.

[20] J. Aguado, J.M. Arsuaga, A. Arencibia, M. Lindo, V. Gascón, J. Hazard. Mater. 163 (2009) 213-221.

[21] S. Prakash, M. Kumar, B.P. Tripathi, V.K. Shahi, Chem. Eng. J. 162 (2010) $28-36$.

[22] Y. Li, W. Luo, N. Qin, J. Dong, J. Wei, W. Li, S. Feng, J. Chen, J. Xu, A.A. Elzatahry, M. H. Es-Saheb, Y. Deng, D. Zhao, Angew. Chem. Int. Ed. 53 (2014) 9035 -9040 .

[23] Y. Deng, D. Qi, C. Deng, X. Zhang, D. Zhao, J. Am. Chem. Soc. 130 (2008) 28-29.

[24] J. Fan, X. Ran, Y. Ren, C. Wang, J. Yang, W. Teng, L. Zou, Y. Sun, B. Lu, Y. Deng, D. Zhao, Langmuir 32 (2016) 9922-9929.

[25] P. Kumar, V.V. Guliants, Microporous Mesoporous Mater. 132 (2010) 1-14.

[26] K. Waldron, Z. Wu, W.D. Wu, W. Liu, D. Zhao, X.D. Chen, C. Selomulya, J. Mater. Chem. A 2 (2014) 19500-19508.

[27] C.T. Kresge, M.E. Leonowicz, W.J. Roth, J.C. Vartuli, J.S. Beck, Nature 359 (1992) 710-712.

[28] Y. Liu, J. Qiu, Y. Jiang, Z. Liu, M. Meng, L. Ni, C. Qin, J. Peng, Microporous Mesoporous Mater. 234 (2016) 176-185.

[29] A. Heidari, H. Younesi, Z. Mehraban, Chem. Eng. J. 153 (2009) 70-79.

[30] L.C.C.D. Silva, L.B.O.D. Santos, G. Abate, I.C. Cosentino, M.C.A. Fantini, J.C. Masini, J.R. Matos, Microporous Mesoporous Mater. 110 (2008) 250-259.

[31] R. He, W. Li, D. Deng, W. Chen, H. Li, C. Wei, Y. Tang, J. Mater. Chem. A 3 (2015) 9789-9798.

[32] M. Meng, X. Meng, Y. Liu, Z. Liu, J. Han, Y. Wang, M. Luo, R. Chen, L. Ni, Y. Yan, J. Hazard. Mater. 278 (2014) 134-143.

[33] M.S. Moorthy, P.K. Tapaswi, S.S. Park, A. Mathew, H.J. Cho, C.S. Ha, Microporous Mesoporous Mater. 180 (2013) 162-171.

[34] D. Wang, X.Q. Guo, C.X. Wang, Y.N. Wang, R. Zhong, X.H. Zhu, L.H. Cai, Z.W. Gao, X.F. Hou, Adv. Synth. Catal. 355(2013) 1117-1125.

[35] H. Cao, X.H. Zhu, D. Wang, Z.k. Sun, Y.H. Deng, X.F. Hou, D.Y. Zhao, ACS Catal. 5 (2015) 27-33.

[36] J.F. Zhang, M.D. Wang, X.Q. Guo, S. Liu, H. Cao, Y.L. Li, Q. Zhou, X.F. Hou, Catal. Lett. 145 (2015) 2001-2009.

[37] F. Blasberg, M. Bolte, M. Wagner, H.W. Lerner, J. Organomet. Chem. 696 (2011) 3593-3600. 
[38] C.R.T. Tarley, F.N. Andrade, H.D. Santana, D.A.M. Zaia, L.A. Beijo, M.G. Segatelli, React. Funct. Polym. 72 (2012) 83-91.

[39] C.C. Kang, W.M. Li, L. Tan, H. Li, C.H. Wei, Y.W. Tang, J. Mater. Chem. A 1 (2013) 7147-7153.

[40] X. Guo, Y. Deng, B. Tu, D. Zhao, Langmuir 26(2) (2010) 702-708

[41] V. Elumalai, S. Dharmalingam, Microporous Mesoporous Mater. 236 (2016) 260-268.

[42] K. Ladewig, A. Seifert, H. Hahn, M. Hietschold, N. Moszner, P. Burtscher, S. Spange, J. Mater. Chem. 22 (2012) 3839-3852.

[43] P. Sharma, A. P. Singh, Catal. Sci. Technol. 4 (2014) 2978-2989.

[44] Y. Xu, X. Sun, D. Wu, Y. Sun, Y. Yang, H. Yuan, F. Deng, Z. Wu, J. Solution Chem. 36 (2007) 327-344.

[45] L. Zhao, S. Wang, Y. Wu, Q. Hou, Y. Wang, S. Jiang, J. Phys. Chem. C 111 (2007) 18387-18391.

[46] I. Slowing, B.G. Trewyn, V.S.Y. Lin, J. Am. Chem. Soc. 128 (2006) 14792-1479.

[47] D. Carmona, F. Balas, J. Santamaria, Mater. Res. Bull. 59 (2014) 311-322.

[48] F. Yang, S. Gao, C. Xiong, H. Wang, J. Chen, Y. Kong, Chin. J. Catal. 36 (2015) 1035-1041.

[49] O. Ersen, J. Parmentier, L.A. Solovyov, M. Drillon, C. Pham-Huu, J. Werckmann, P. Schultz, J. Am. Chem. Soc. 130 (2008) 16800-16806.

[50] M. Wang, Z. Sun, Q. Yue, J. Yang, X. Wang, Y. Deng, C. Yu, D. Zhao, J. Am. Chem. Soc. 136 (2014) 1884-1892.

[51] D. Zhao, J. Feng, Q. Huo, N. Melosh, G.H. Fredrickson, B.F. Chmelka, G.D. Stucky, Science 279 (1998) 548-552.

[52] N. Teabpinyok, M. Chareonpanich, S. Samingprai, J. Limtrakul, Can. J. Chem. Eng. 90 (2012) 881-887.

[53] D. Pére-Quintanilla, A. Sánchez, I.D. Hierro, M. Fajardo, I. Sierra, J. Colloid Interface Sci. 313 (2007) 551-562.

[54] Y.K. Tsoi, Y.M. Ho, K.S.Y. Leung, Talanta 89 (2012) 162-168.

[55] M.E. Argun, S. Dursun, Bioresour. Technol. 99 (2008) 2516-2527.

[56] E. Demirbas, N. Dizge, M.T. Sulak, M. Kobya, Chem. Eng. J. 148 (2009) 480-487.

[57] N.Y. Mezenner, A. Bensmaili, Chem. Eng. J. 147 (2009) 87-96

[58] Y. Liu, Z. Liu, Y. Wang, J. Dai, J. Gao, J. Xie, Y. Yan, Microchim. Acta 172 (2011) 309-317.

[59] G. Gyananath, D.K. Balhal, Cellul. Chem. Technol. 46 (2012) 121-124.

[60] S. Wei, Y. Liu, M. Shao, L. Liu, H. Wang, Y. Liu, RSC Adv. 4 (2014) 29715-29723.

[61] S.P. Kuang, Z.Z. Wang, J. Liu, Z.C. Wu, J. Hazard. Mater. 260 (2013) 210-219.

[62] S. Luo, X. Xu, G. Zhou, C. Liu, Y. Tang, Y. Liu, J. Hazard. Mater. 274 (2014) $145-155$.

[63] V. Sarin, K.K. Pant, Bioresour. Technol. 97 (2006) 15-20.

[64] A.R. Iftikhar, H.N. Bhatti, M.A. Hanif, R. Nadeem, J. Hazard. Mater. 161 (2009) 941-947. 
[65] M. Özacar, İ. Ayhan Şengil, H. Türkmenler, Chem. Eng. J. 143 (2008) 32-42.

\section{Graphical abstract}

Scheme 1: Preparation procedures of Pb-IIMS-SBA-15, Pb-IIMS-MCM-41, $\mathrm{Pb}-\mathrm{IIMS}-\mathrm{FDU}-12$.

Fig. 1. FT-IR spectra of Pb-IIMS.

Fig. 2. (a) Solid-state ${ }^{29} \mathrm{Si}$ NMR spectra of Pb-IIMS; (b) Solid-state ${ }^{13} \mathrm{C}$ NMR spectra of $\mathrm{Pb}$-IIMS.

Fig. 3. SEM micrographs of Pb-IIMS-SBA-15 (a), Pb-IIMS-MCM-41 (b), Pb-IIMS-FDU-12 (c).

Fig. 4. TEM images of Pb-IIMS-SBA-15 (a1), (a2); Pb-IIMS-MCM-41 (b1), (b2); Pb-IIMS-FDU-12 (c1), (c2).

Fig. 5. EDX spectrum of Pb-IIMS

Fig. 6. $\mathrm{N}_{2}$ adsorption-desorption isotherms and pore size distribution (inset) of Pb-IIMS-SBA-15 (a), Pb-IIMS-MCM-41 (b) and Pb-IIMS-FDU-12 (c)

Fig. 7. Small angle XRD of Pb-IIMS-SBA-15 (a), Pb-IIMS-MCM-41 (b), Pb-IIMS-FDU-12 (c).

Fig. 8. Effect of $\mathrm{pH}$ on the extraction efficiency of IIMS for $\mathrm{Pb}(\mathrm{II})$.

Fig. 9. Adsorption isotherms of IIMS (a) and NIMS (b) at different original concentrations of $\mathrm{Pb}(\mathrm{II})$. Influence of contact time on IIMS (c).

Fig. 10. Selectivity of Pb-IIMS-SBA-15, Pb-IIMS-MCM-41, Pb-IIMS-FDU-12, and their corresponding NIPs. 
Fig. 11. Reusability of Pb-IIMS-MCM-41 


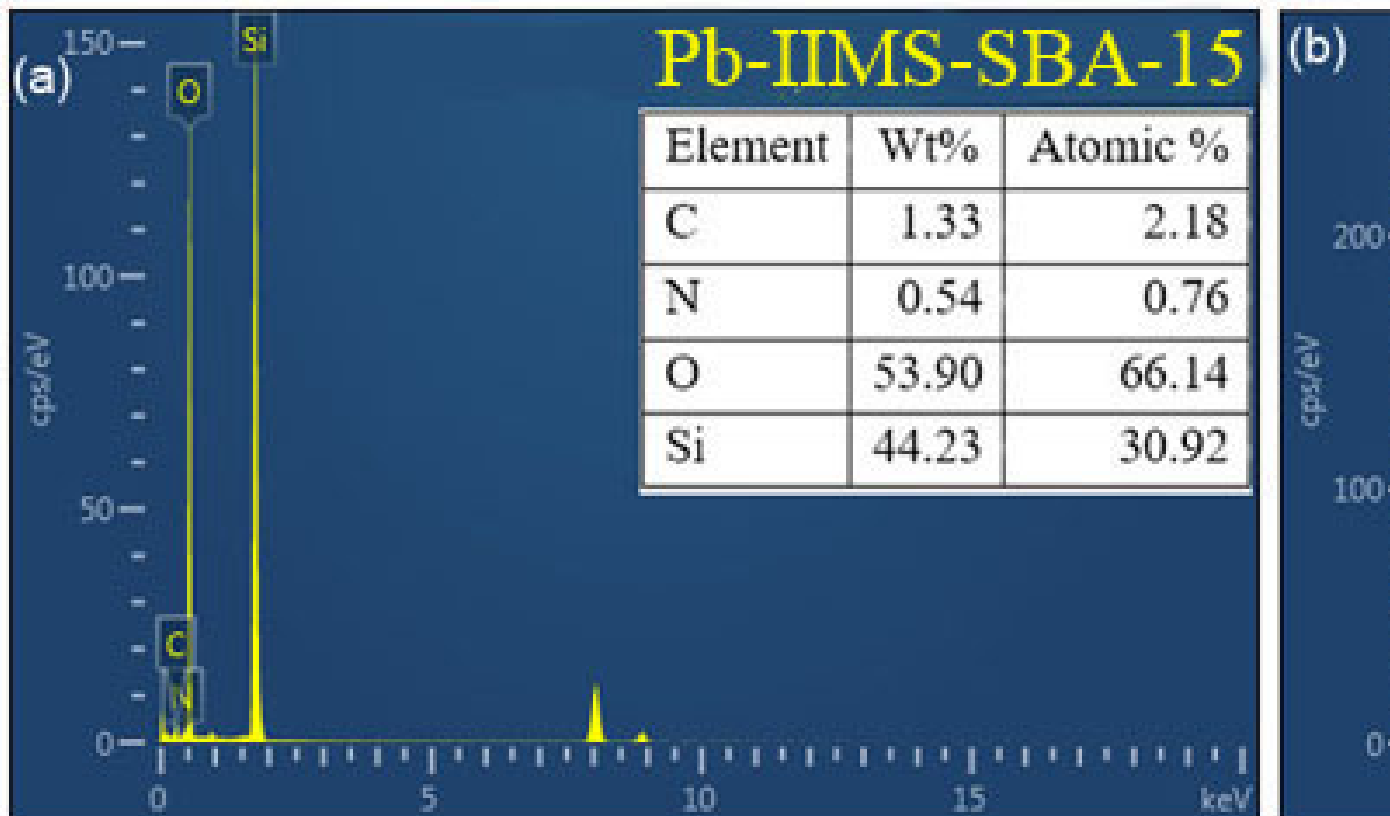

Pb-IIMS-MCM-41

\begin{tabular}{|l|r|r|}
\hline Element & $\mathrm{Wt} \%$ & Atomic $\%$ \\
\hline $\mathrm{C}$ & 5.01 & 8.20 \\
\hline $\mathrm{N}$ & 1.08 & 1.52 \\
\hline $\mathrm{O}$ & 46.43 & 57.04 \\
\hline $\mathrm{Si}$ & 47.48 & 33.23 \\
\hline
\end{tabular}

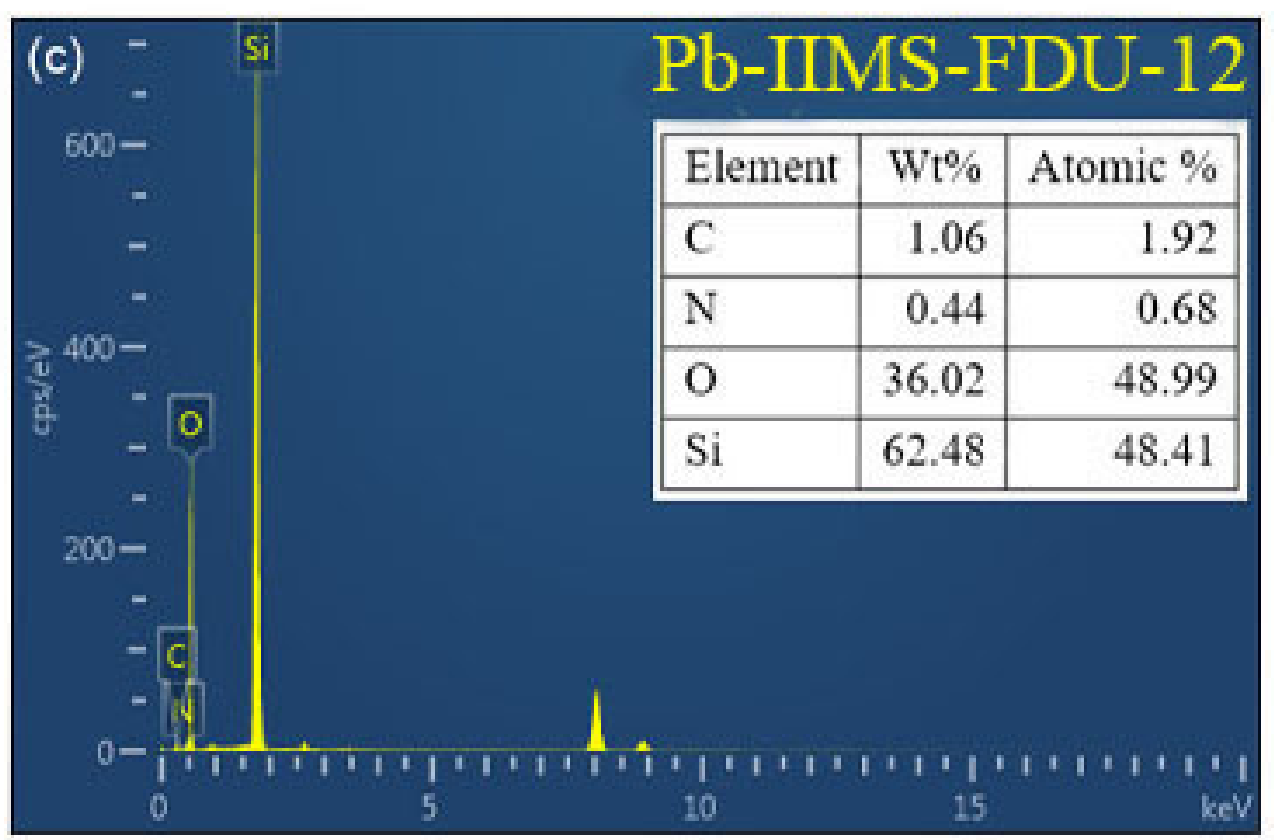

kev 15 
(a)
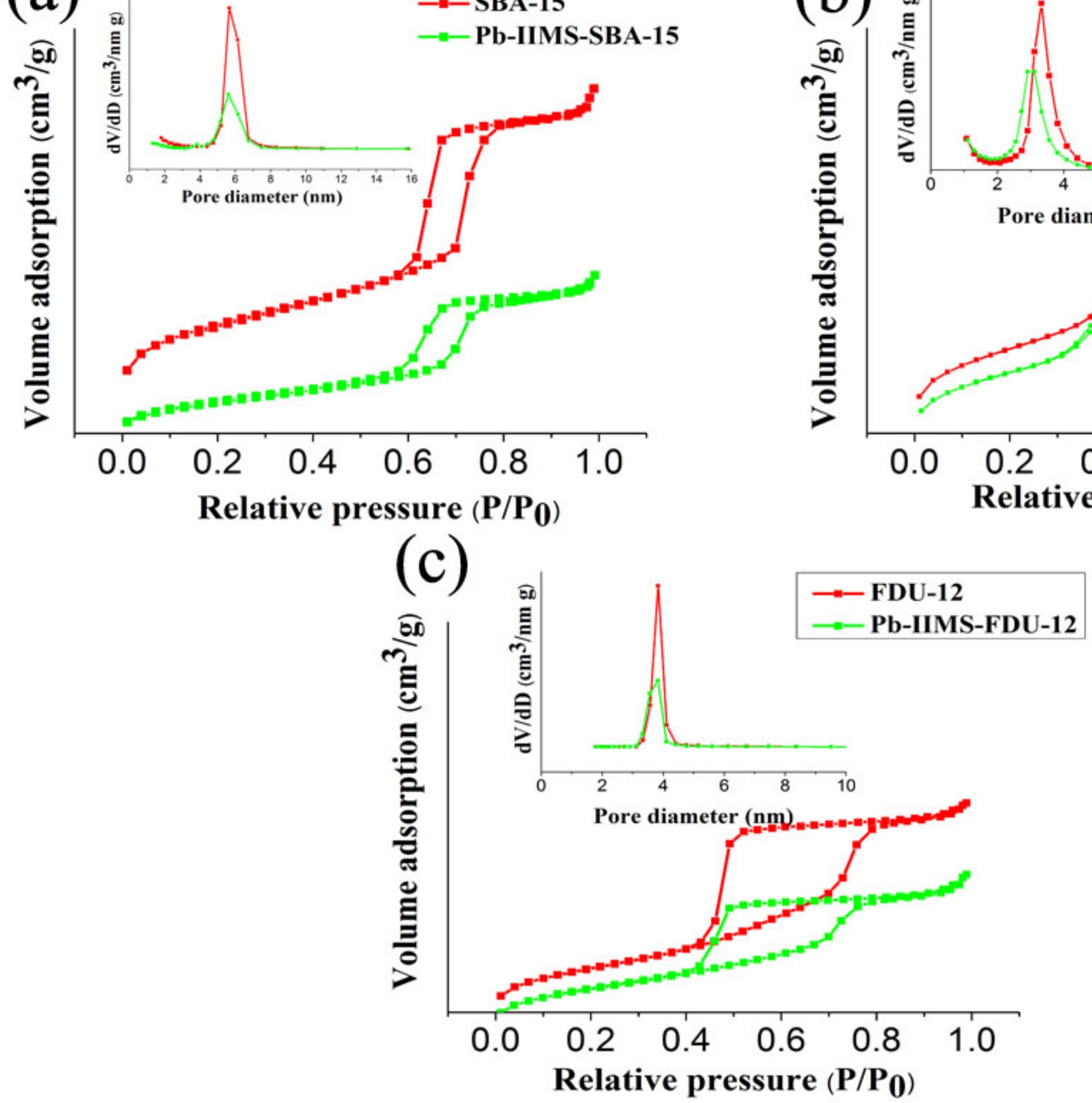

(b) $\underset{\equiv}{\stackrel{\infty}{=}} \quad ; \quad \longrightarrow$ МСM-41 Pb-IIMS-MCM-41
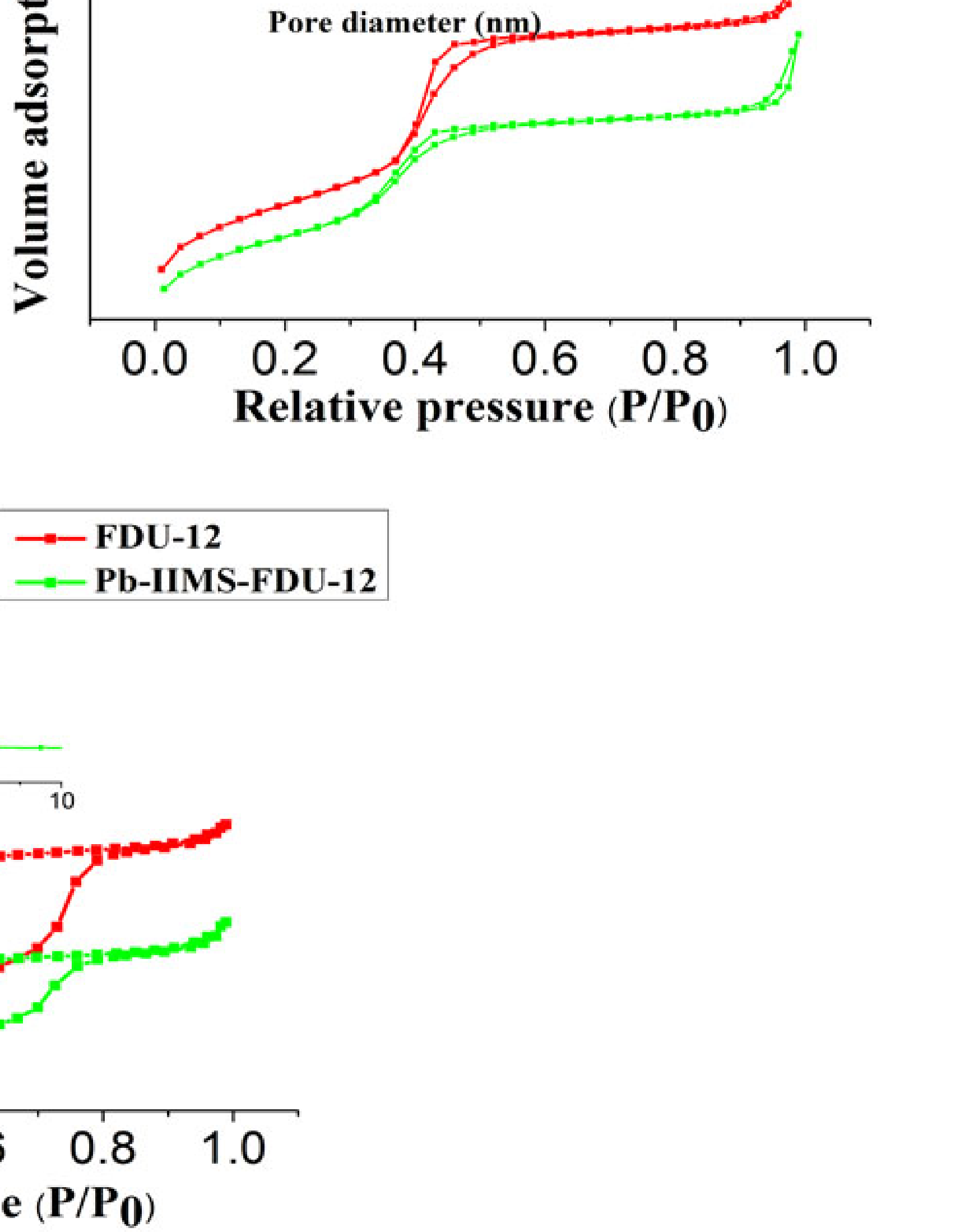


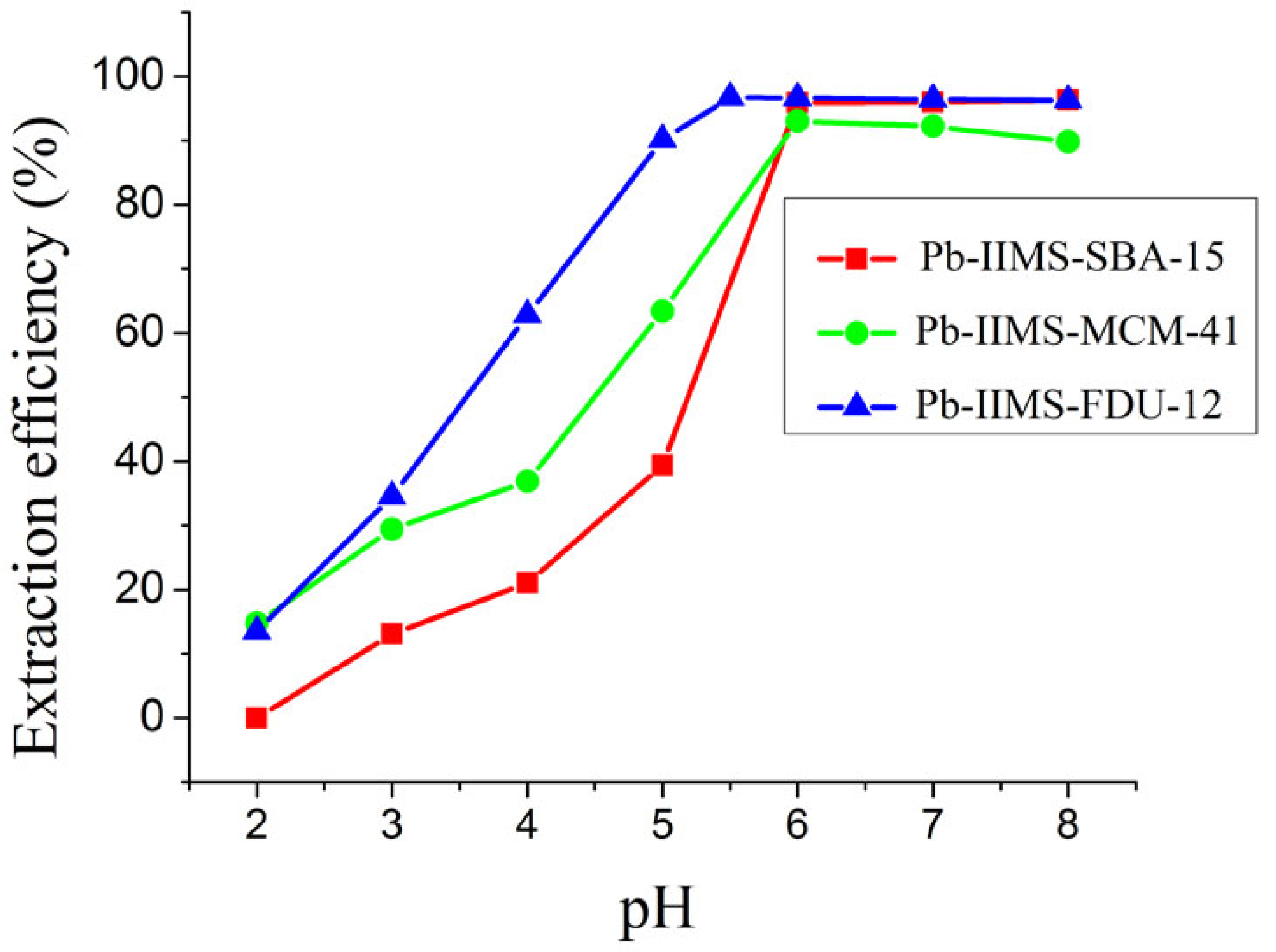


(a)

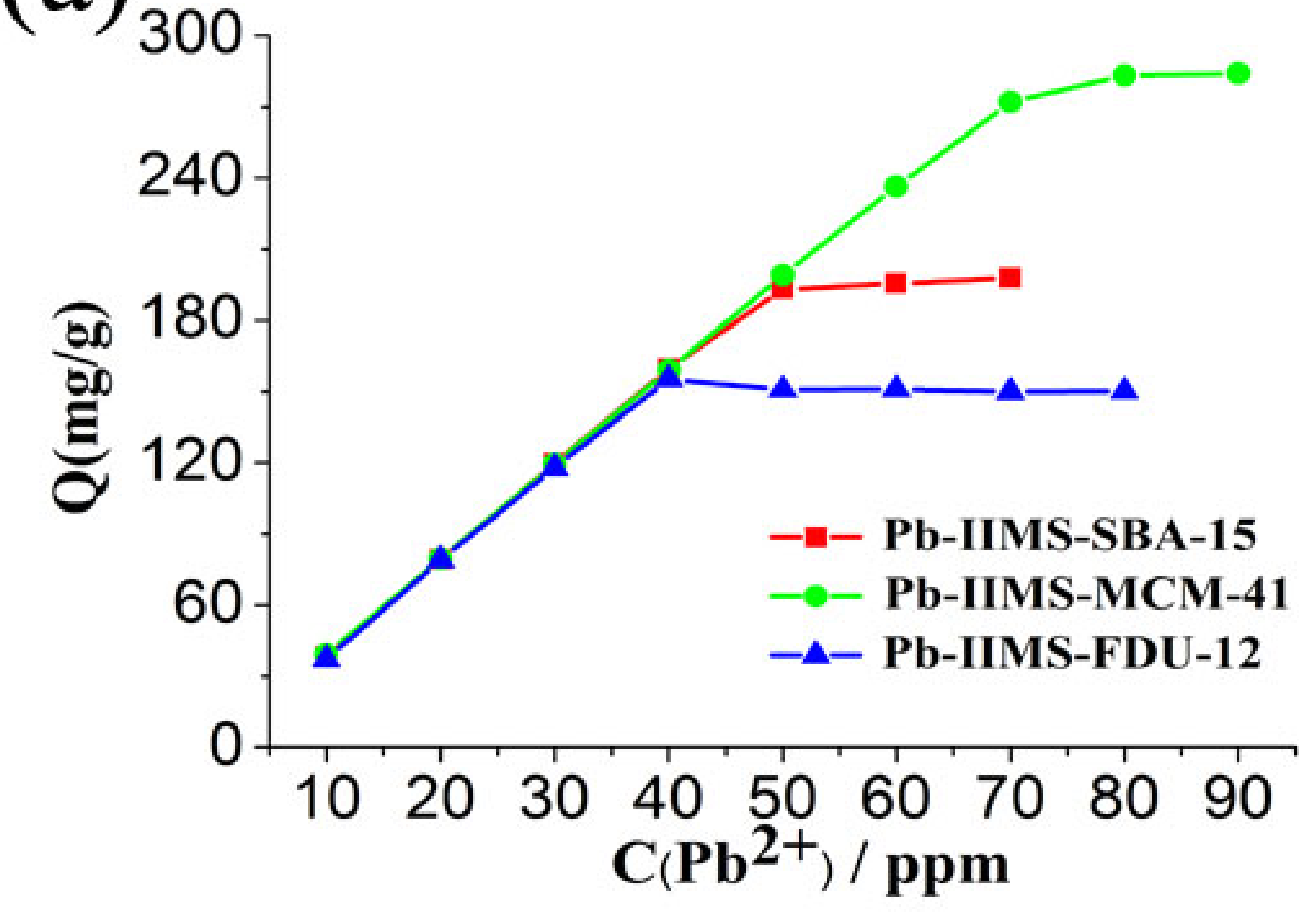

(b)
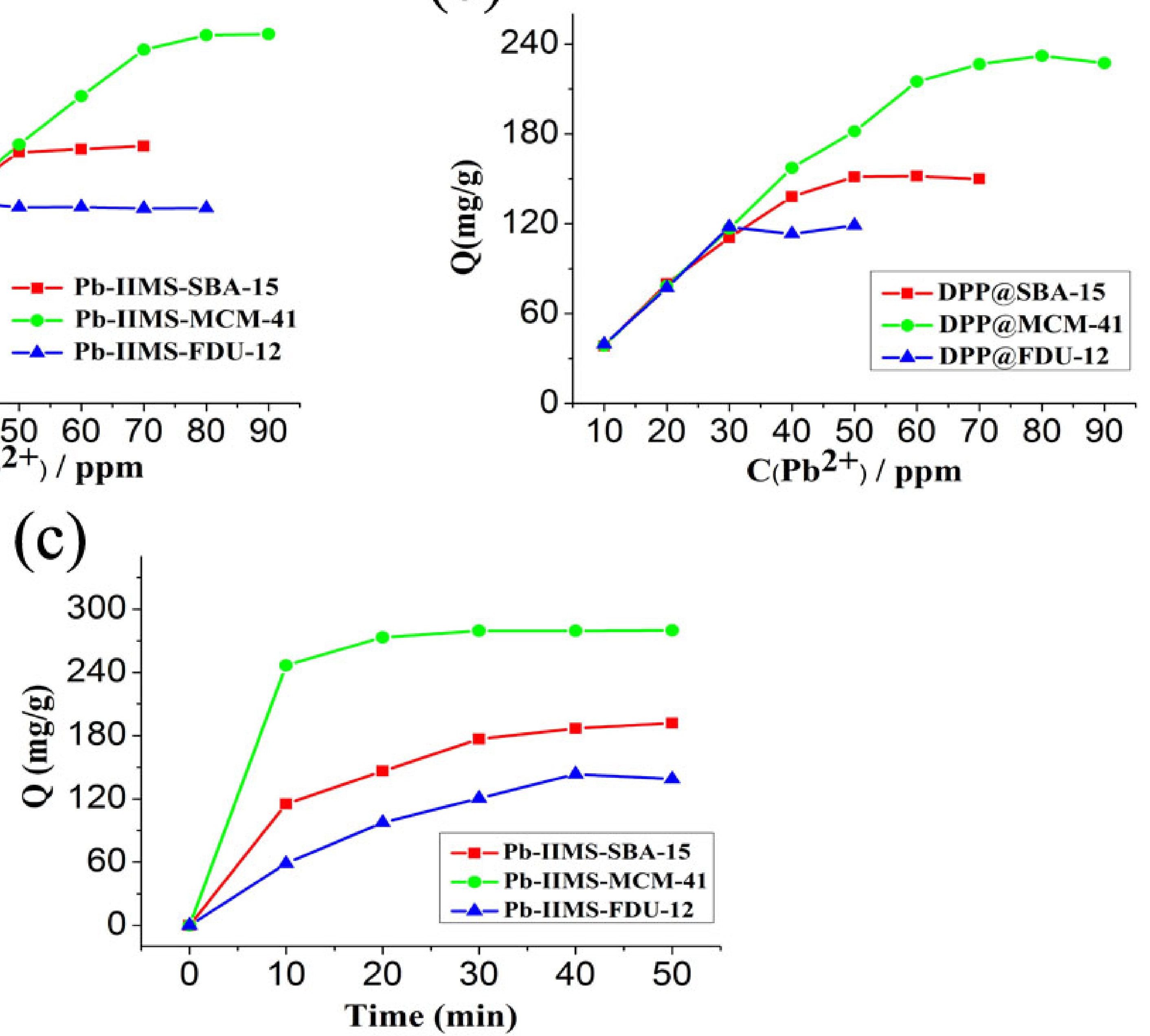


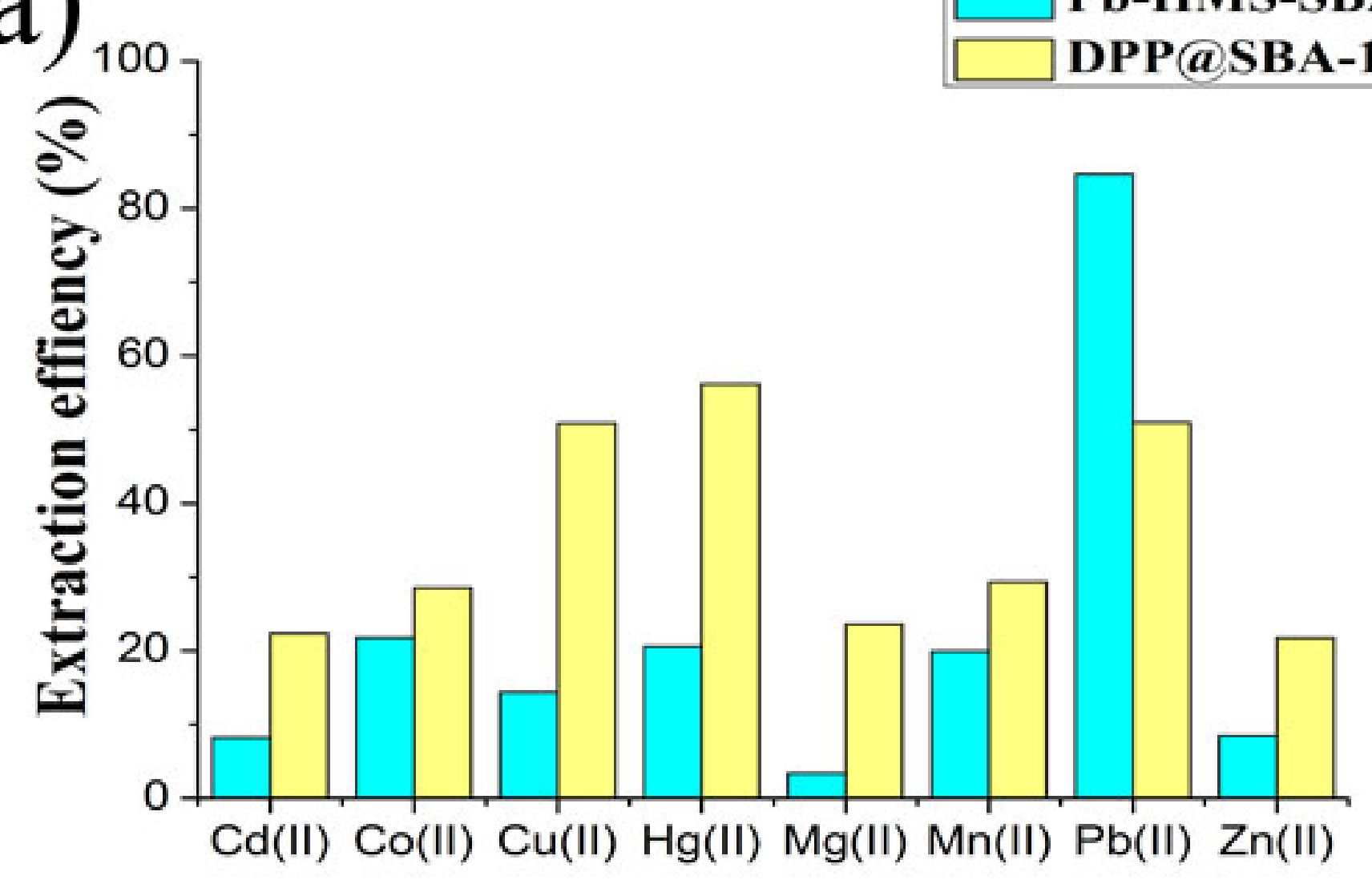

Ion species (b)

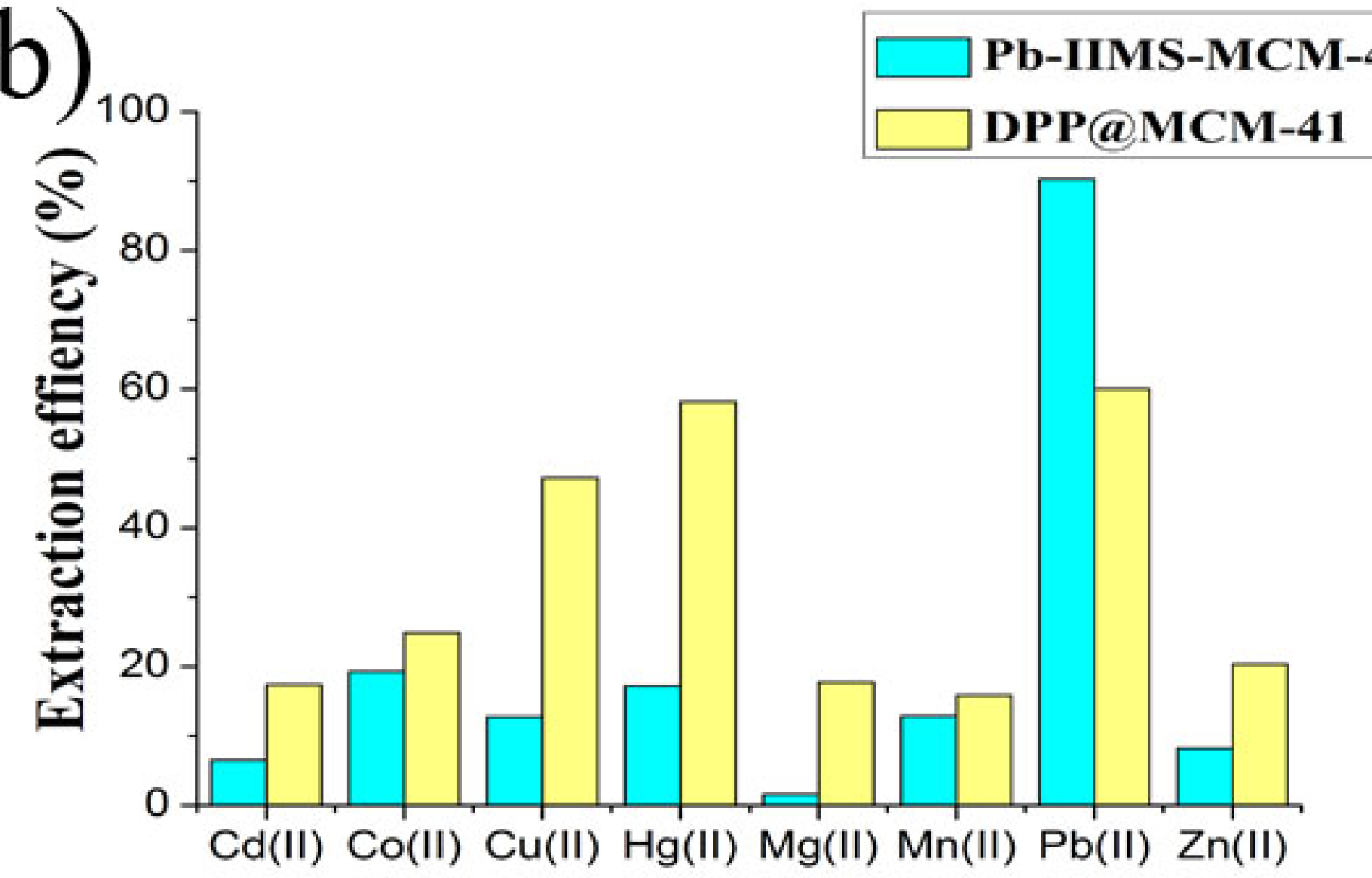

Ion species

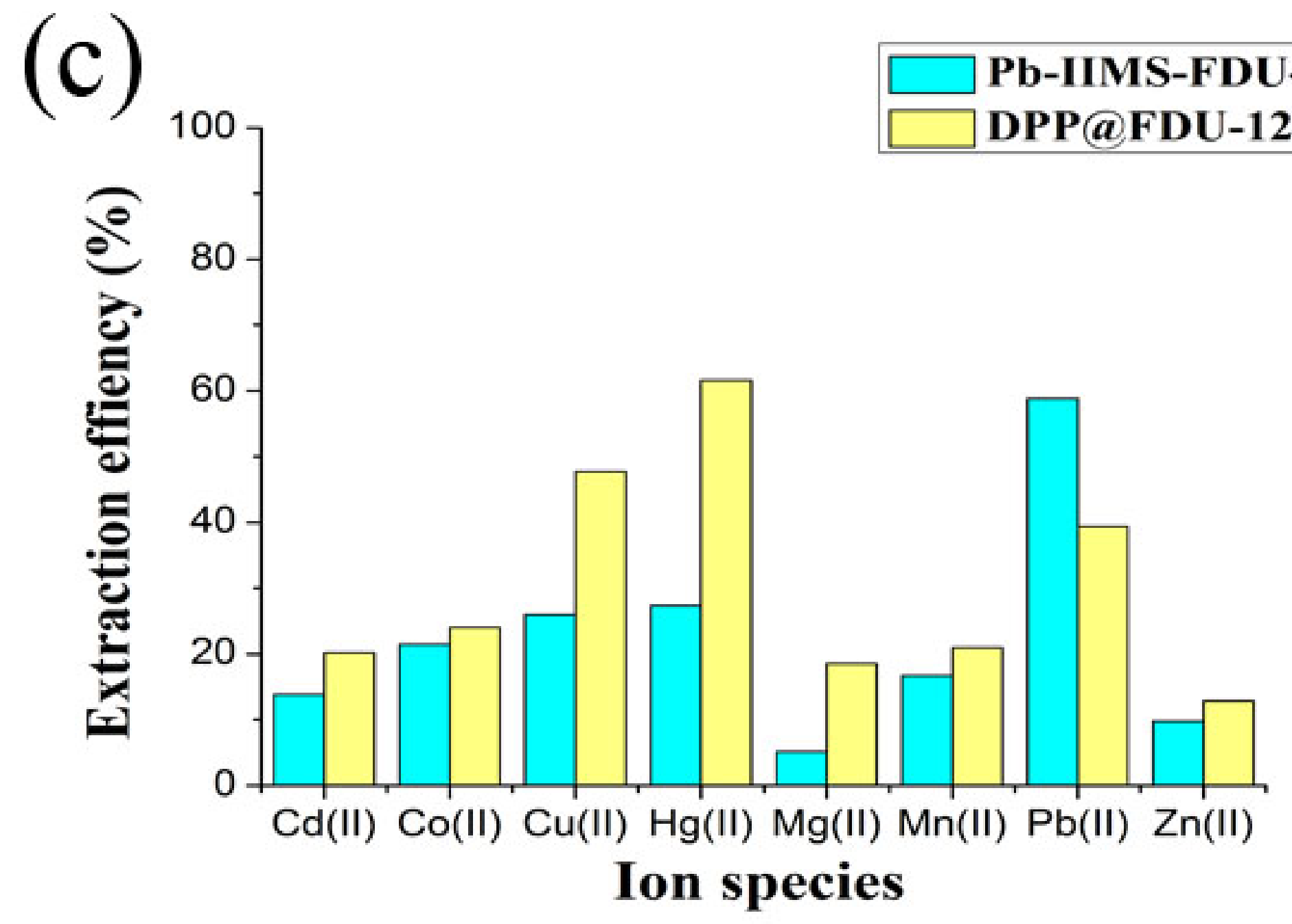




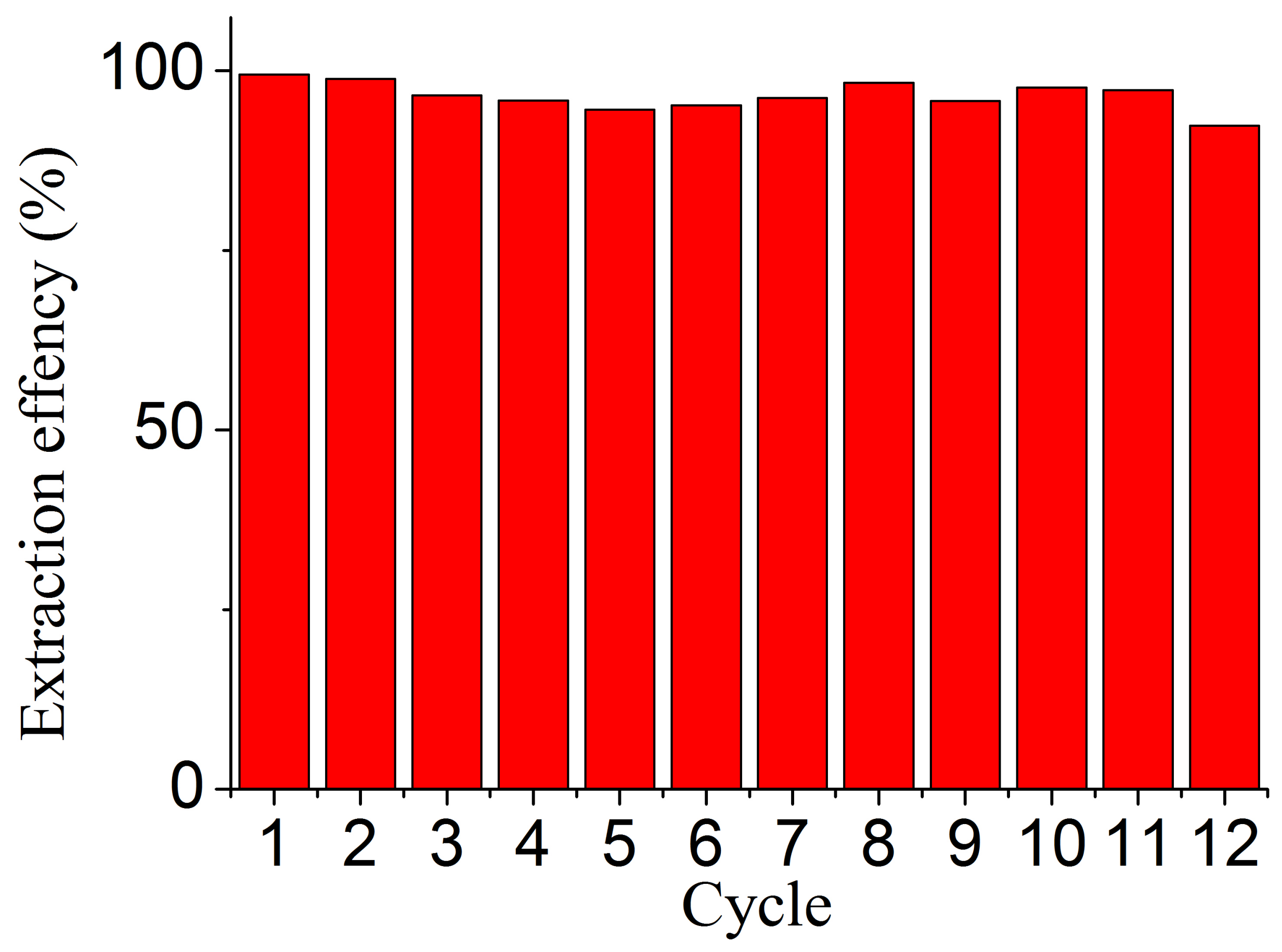


